\title{
AVANÇOS RECENTES NA SÍNTESE DO REMDESIVIR, MOLNUPIRAVIR (EIDD-2801) E TENOFOVIR: MOLÉCULAS PROMISSORAS NO TRATAMENTO DA COVID-19
}

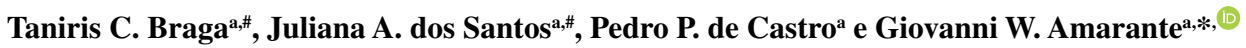

a'Departamento de Química, Universidade Federal de Juiz de Fora, Campus Martelos, 36036-900 Juiz de Fora - MG, Brasil

Recebido em 24/06/2021; aceito em 12/07/2021; publicado na web em 10/08/2021

RECENT ADVANCES IN THE SYNTHESIS OF REMDESIVIR, MOLNUPIRAVIR (EIDD-2801) AND TENOFOVIR: PROMISING MOLECULES IN THE TREATMENT OF COVID-19. The search for new treatments to contain the Covid-19 pandemic has highlighted the importance of nucleoside antivirals, such as Remdesivir, Tenofovir and Molnupiravir. Over the last two years, these molecules have been intensely investigated as promising alternatives against SARS-CoV-2 virus. Considering the increasingly demand for those substances, several research groups are intensely investigating synthetic developments in order to obtain these nucleoside derivatives and their intermediates in a fast, efficient and accessible manner. In this context, this review aims to in-depth present the recent advances concerning the preparation of Remdesivir, Tenofovir and Molnupiravir. Aspects involving differences in the starting materials and reagents, as well as the advantages and limitations of each protocol would be carefully disclosed. Moreover, the use of synthetic tools, such as flow chemistry, organocatalysis and biocatalysis, would also be detailed. Finally, this review also presents aspects involving the scale-up of these transformations, including discussions about stereo- and diastereoselectivity, as well as product isolation details. In summary, an overview of the existing synthetic strategies for these active pharmaceutical ingredients (APIs) are presented.

Keywords: nucleoside; Covid-19; antiviral; remdesivir.

\section{INTRODUÇÃOO}

Análogos de nucleosídeos vêm desempenhando um papel crucial nas terapias antivirais desde a aprovação da primeira droga antiviral, a idoxuridina, em 1963 para o tratamento do vírus herpes simplex. ${ }^{1,2}$ Desde então, diversos análogos nucleosídicos têm sido estudados e aprovados para o tratamento de infecções causadas por uma diversidade de vírus com potencial patogênico, como o vírus da hepatite $\mathrm{C}$ e o citomegalovírus.

A busca por novas moléculas dessa classe se intensificou com surgimento de linhagens patogênicas e com alta transmissibilidade, em especial de vírus do gênero Betacoronavirus, como os responsáveis pela síndrome respiratória aguda grave (do inglês SARS, em 2002), a síndrome respiratória do Oriente Médio (do inglês MERS, em 2012) e, mais recente, do vírus SARS-CoV-2, causador da Covid-19. Desde o início da pandemia de Covid-19, a comunidade científica tem dedicado um esforço sem precedentes, não só na compreensão do processo patológico e em suas consequências clínicas, mas também na busca por alternativas de tratamentos e vacinas. ${ }^{3}$ No que tange à área Química, diversos grupos descreveram estudos envolvendo desde ensaios pré-clínicos de novos candidatos a fármacos, à prospecção de moléculas de fármacos comerciais envolvendo a estratégia de reposicionamento de fármacos. ${ }^{4}$ Dentre os poucos compostos promissores encontrados nesses trabalhos, destacam-se os análogos de nucleosídeos, como o Remdesivir (1), ${ }^{5-7}$ Tenofovir (2) ${ }^{8,9}$ e, mais recentemente, o Molnupiravir (3) ${ }^{10,11}$ (Figura 1).

\section{REMDESIVIR}

O Remdesivir (1) consiste em um análogo de nucleosídeo originalmente desenvolvido pela empresa Gilead Sciences para tratamento do vírus Ebola. ${ }^{12}$ Recentemente, esse pró-fármaco tem sido alvo de intenso interesse da comunidade científica, devido à sua atividade antiviral contra o vírus SARS-CoV-2, responsável pela Covid-19. ${ }^{13,14}$ Esse interesse pode ser evidenciado através do fato de que, atualmente, o Remdesivir é o único medicamento não baseado em anticorpos monoclonais aprovado pelo Food and Drug Administration (FDA), ${ }^{15}$ dos Estados Unidos, e pela agência Nacional de Vigilância Sanitária, ${ }^{16}$ do Brasil, para tratamento da Covid-19.

Diversos estudos envolvendo o mecanismo de ação do Remdesivir têm sido reportados desde o início da pandemia de Covid-19., De maneira geral, encontra-se bem estabelecido que a atividade antiviral está relacionada à inibição da enzima RNA polimerase dependente de RNA do vírus (RpdR), uma enzima diretamente envolvida no seu processo de replicação. ${ }^{17}$ Essa inibição é associada ao produto de metabolismo in vivo do Remdesivir 4, que contém um grupamento trifosfato em vez da fosforamida, sendo reconhecido e

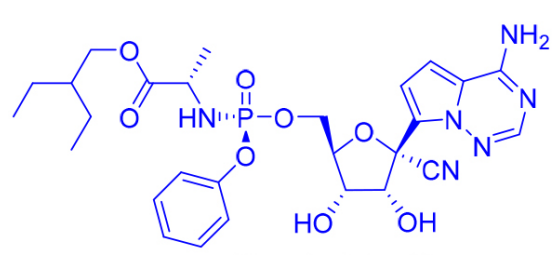

(Remdesivir - 1)<smiles>C[C@H](Cn1cnc2c(N)ncnc21)OCP(=O)(O)O</smiles>

(Tenofovir - 2)<smiles>CC(C)C(=O)OC[C@H]1O[C@@H](n2ccc(NO)nc2=O)[C@H](O)[C@@H]1O</smiles>

(Molnupiravir - 3)

Figura 1. Estruturas químicas do Remdesivir, Tenofovir e Molnupiravir

*e-mail: giovanni.amarante@ufjf.edu.br

\#Essas autoras contribuíram igualmente para a elaboração deste estudo. 
A)<smiles>CCC(CC)COC(=O)[C@H](C)NP(=O)(O)OC[C@H]1O[C@](Oc2ccccc2)(c2ccc3c(N)ncnn23)[C@H](O)[C@@H]1O</smiles>

(Remdesivir - 1)

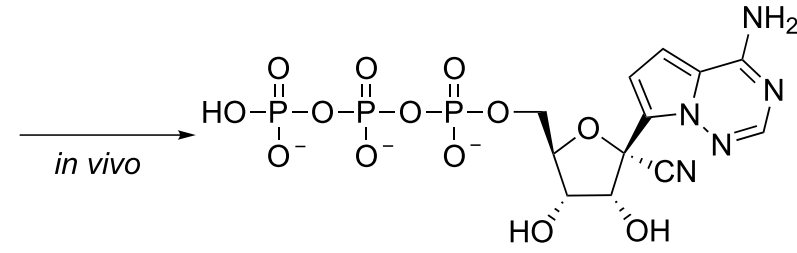

(4)

B)

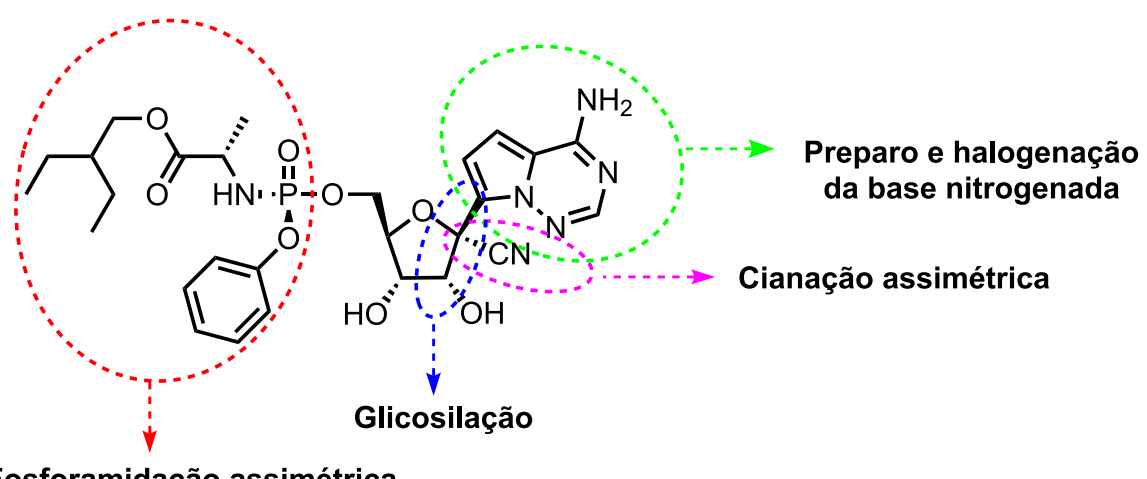

Fosforamidação assimétrica

Esquema 1. A) Remdesivir e seu intermediário ativo; B) Principais desafios sintéticos envolvidos na síntese do Remdesivir

utilizado pela RpdR viral como um análogo da adenosina trifosfato (Esquema 1A). ${ }^{18,19}$

Dentre os principais desafios sintéticos envolvidos no preparo do Remdesivir (Esquema 1B), merecem destaque o preparo da base pirrolotriazina, a etapa de glicosilação desta com o derivado de carboidrato ribolactona, a cianação assimétrica e a fosforamidação assimétrica. A relativa complexidade estrutural dessa molécula, que inclui ainda a presença de seis centros esterogênicos, faz com que o custo do tratamento com esse medicamento encontre-se atualmente na casa dos milhares de dólares por paciente. ${ }^{20}$ Assim, diversos grupos de pesquisa em síntese orgânica têm desenvolvido metodologias alternativas visando a simplificação do preparo desse fármaco e, consequentemente, uma maior acessibilidade ao medicamento.

\section{Preparo e halogenação da base nitrogenada}

A preparação da base nitrogenada não-natural pirrolo[2,1- $f]$ $[1,2,4]$ triazina $(5)$ geralmente se dá a partir da ciclização, via intermediário formamidino, do 1-aminopirrol-2-carbonitrila (6), o qual, por sua vez, pode ser acessado a partir do pirrol 7 ou seus derivados. Das cinco rotas disponíveis na literatura, quatro seguem essa abordagem, ilustrada como retrossíntese no Esquema 2.

Klein e colaboradores foram os responsáveis pela primeira rota sintética de acesso à base pirrolotriazina (5), a qual foi obtida em rendimento global de $28 \%$, em duas etapas, a partir do 2-pirrolcarboxaldeído (8) (Esquema 3). ${ }^{21}$ A proposta dos pesquisadores foi apostar na versatilidade do ácido hidroxilamina- $O$ sulfônico (HOSA) para promover tanto a cianação (via intermediário oxima- $O$-sulfonato) quanto a $N$-aminação de 8 , em uma única etapa, na presença de $\mathrm{KOH}$. No entanto, esta metodologia apresentou baixa quimiosseletividade, fornecendo o intermediário reativo 1-aminopirrol-2-carbonitrila (6) em apenas $43 \%$ de rendimento e também o produto não-aminado pirrol-2-carbonitrila (9) como um subproduto indesejado em $37 \%$ de rendimento. Por outro lado, a etapa de formação da pirrolotriazina com acetato de formamidina, embora empregue grande excesso dos reagentes, mostrou-se eficiente, em termos operacionais e de rendimento (66\%). Merece destaque o tempo reacional total relativamente curto $(8 \mathrm{~h})$ para acesso à base nitrogenada pela rota de Klein, fornecendo o heterociclo 5 em $28 \%$ de rendimento global.

A rota empregada na produção comercial do Remdesivir, descrita pela Bayer em 2006, consiste em uma sequência linear de quatro etapas e faz uso de 2,5-dimetoxitetraidrofurano (10) e terc-butilcarbazato (11) como materiais de partida (Esquema 4).22,23 A nucleobase não-natural 5 é produzida em $31 \%$ de rendimento global após etapas sequenciais de formação de derivado aminopirrolínico 12, introdução de grupo nitrila na posição 2 do anel pirrolidínico utilizando isocianato de clorosulfonila, com formação do derivado 13, seguidas de desproteção do carbamato para fornecer 1-aminopirrol-2-carbonitrila (6). Finalmente, de modo similar à proposta de Klein, a reação de ciclização é realizada com acetato de formamidina, utilizando $\mathrm{K}_{3} \mathrm{PO}_{4}$ em vez de $\mathrm{K}_{2} \mathrm{CO}_{3}$, levando ao produto desejado 5 em rendimento superior ( $81 \%$ ). Embora esse procedimento já esteja eficientemente escalonado, cabe ressaltar que tanto a utilização de insumos derivatizados como materiais de partida, a qual implica no aumento do número de etapas sintéticas (2 etapas extras para preparo do 2,5-dimetoxitetra-hidrofurano (10)<smiles></smiles>

(5)<smiles>N#Cc1cccn1N</smiles>

(6)<smiles>[R]c1cccn1[R]</smiles>

(7) $\mathrm{R}_{1}=\mathrm{H}, \mathrm{CHO}$ $\mathrm{R}_{2}=\mathrm{H}, \mathrm{NHBOC}$

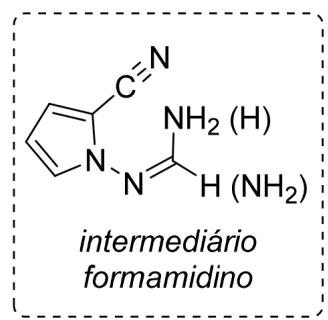




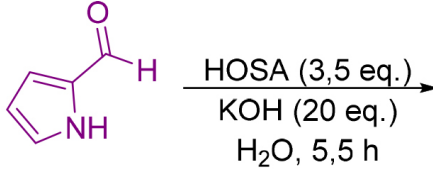

(8)<smiles>N#Cc1cccn1N</smiles>

(6) $43 \%$

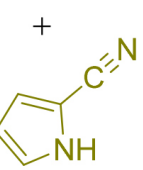

(9) $37 \%$

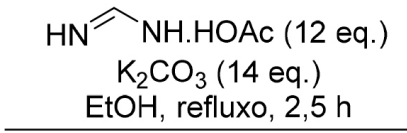

oxima-O-sulfonato<smiles>Nc1ncnn2cccc12</smiles>

(5) $66 \%$

(global: $28 \%$ )

Esquema 3. Rota sintética de Klein e colaboradores para obtenção da pirrolotriazina 5

partindo do furano e 4 etapas extras para síntese do terc-butilcarbazato (11) partindo de terc-butanol e amônia), quanto a necessidade da etapa adicional para clivagem do grupo protetor carbazato, contribuem para a baixa eficiência global do processo.

Recentemente, o grupo de pesquisa de Snead apresentou uma proposta sintética de acesso à base nitrogenada do Remdesivir, de considerável eficiência quando comparada à rota da Bayer (Esquema 5). ${ }^{24} \mathrm{~A}$ síntese envolve um processo one-pot de formação de 9 diretamente a partir do pirrol 14 (sem necessidade de isolamento do cloridrato 15), seguido de uma etapa de $N$-aminação sob fluxo contínuo utilizando monocloroamina $\left(\mathrm{NH}_{2} \mathrm{Cl}\right)$. Os autores descrevem um escalonamento do processo e o rendimento global alcançado é de $59 \%$, o maior já descrito para a preparação da pirrolotriazina 5. Como principal desvantagem dessa metodologia, destaca-se o longo tempo reacional total requerido para acesso à base nitrogenada ( 34 horas).
Em termos cronológicos, a quarta proposta sintética descrita na literatura para o preparo de 5 é resultado de uma colaboração entre os grupos de pesquisa de Sarpong e Garg. ${ }^{25}$ Assim como a rota da Bayer, essa estratégia utiliza 2,5-dimetoxitetra-hidrofurano (10) como material de partida de uma sequência linear de quatro etapas. Essa abordagem alternativa de acesso à nucleobase tem como etapa-chave a ciclização da cianoamidina $\mathbf{1 8}$, via substituição eletrofílica aromática (Esquema 6). Nesse protocolo o intermediário 18 é obtido a partir da condensação da cianamida 17 com a formamida 16 e, embora seja inovador no que se refere ao uso de intermediários alternativos, a proposta sintética leva a um rendimento global de apenas $16 \%$.

Recentemente, ao revisitar a rota de acesso à 4-aminopirrolo[2,1-f] $[1,2,4]$ triazina (5) descrita por Klein, Amarante e colaboradores reportaram um rendimento global de $39 \%$ ao desenvolver um protocolo linear de três etapas sintéticas que resolve o problema<smiles>COC1CCC(OC)O1</smiles>

Esquema 4. Rota sintética da Bayer para obtenção da pirrolotriazina 5

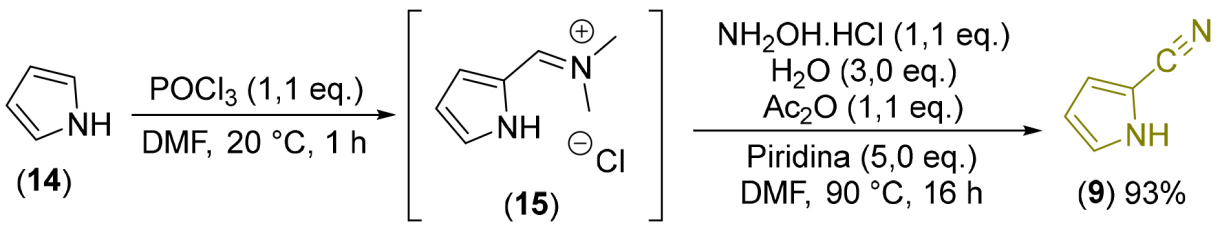<smiles>Nc1ncnn2cccc12</smiles>

(5) $63 \%$

(global: 59\%)

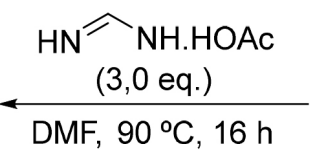

DMF, $90^{\circ} \mathrm{C}, 16 \mathrm{~h}$

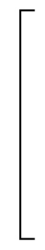

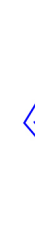

1) $\mathrm{NaH}$ (2,0 eq.) DMF, t.a.

2) $\mathrm{NH}_{2} \mathrm{Cl}, \mathrm{MTBE}$ t.a., 0,5 h 


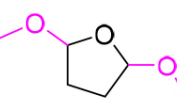

(10)
1) (11), $\mathrm{HCl}, \mathrm{NMP}, 90^{\circ} \mathrm{C}$ (89\% rendimento)

2) $\mathrm{Ac}_{2} \mathrm{O}(5,0$ eq.), $\mathrm{HCOOH}$ $23^{\circ} \mathrm{C}, 0,5 \mathrm{~h}$

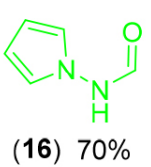

$\mathrm{NC}-\mathrm{NH}_{2}(17)$ $(1,0$ eq.)

$\mathrm{NaOMe}(1,0$ eq. $)$ $\mathrm{MeOH}, 23^{\circ} \mathrm{C}, 1 \mathrm{~h}$

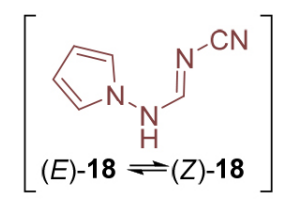

(18) rend. quantitativo

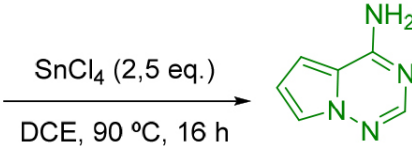

(5) $29 \%$ (global: $16 \%)$

Esquema 6. Rota sintética de Sarpong e Grag para obtenção da pirrolotriazina 5

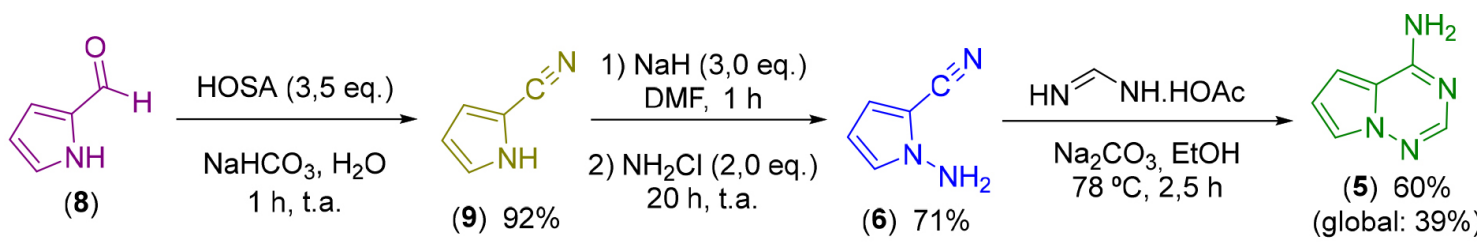

Esquema 7. Rota sintética de Amarante e colaboradores para obtenção da pirrolotriazina 5

da baixa quimiosseletividade da primeira etapa da rota original e utiliza alvejante comercial para geração do agente de $\mathrm{N}$-aminação monocloroamina $\left(\mathrm{NH}_{2} \mathrm{Cl}\right.$ ) (Esquema 7). ${ }^{26}$ Empregando HOSA para a cianação quimiosseletiva do 2-pirrolcarboxaldeído (8), o intermediário 9 foi acessado em $91 \%$ de rendimento, eliminando ainda a etapa de purificação por coluna cromatográfica, necessária na proposta de Klein. Na sequência, a pirrolotriazina $\mathbf{6}$ foi acessada através da $\mathrm{N}$-aminação de 9 com $\mathrm{NH}_{2} \mathrm{Cl}$, gerando o derivado $6 \mathrm{em} 71 \%$ de rendimento, seguido da etapa de ciclização desse intermediáriochave, utilizando modificações sutis na metodologia de Klein.

A halogenação da base nitrogenada 4-aminopirrolo[2,1-f][1,2,4] triazina também tem sido alvo de bastante interesse na literatura, uma vez que esta é uma reação chave para a etapa sintética subsequente de $C$-glicosilação. Nesse contexto, derivados 7-halopirrolotriazina são requeridos nas primeira e segunda gerações de síntese do Remdesivir. Enquanto a 7-bromopirrolo[2,1-f][1,2,4]triazina (19) foi utilizada na primeira geração da síntese do antiviral, na segunda geração esse derivado bromado foi substituído por 7-iodopirrolo[2,1-f][1,2,4] triazina (20), devido ao fato de o derivado iodado ser mais efetivo na troca metal-halogênio requerida nas condições reacionais empregadas para a $C$-glicosilação. ${ }^{27}$ As halo-substituições eletrofílicas em C-2 do núcleo pirrolotriazina são realizadas, empregando-se diferentes agentes como 1,3-dibromo-5,5-dimetilimidazolidina-2,4-diona (21) e $N$-iodosuccinimida (NIS) (22), em DMF, como fontes eletrofílicas de bromo e iodo, respectivamente. Os derivados halogenados são facilmente isolados do meio reacional e obtidos em rendimentos de até $91 \%$ (Esquema 8). ${ }^{26,28}$

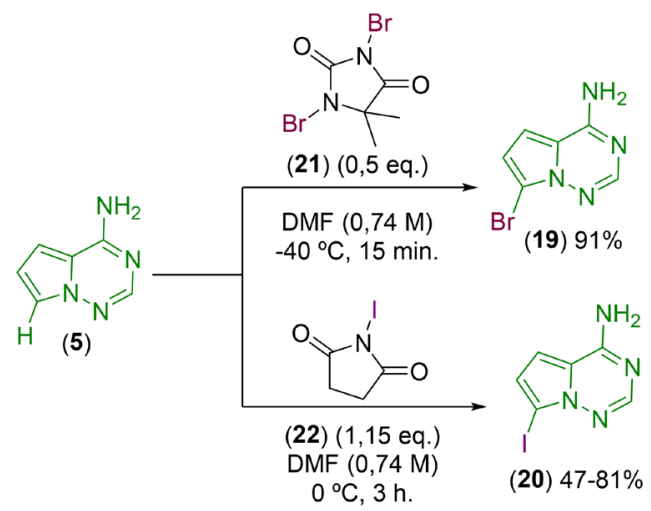

Esquema 8. Halogenação da pirrolotriazina 5

\section{Etapa de $C$-glicosilação}

As reações de $C$-glicosilação são bastante exploradas na síntese de compostos com atividades biológicas. ${ }^{29}$ De maneira geral, essas reações são bastante sensíveis ao ar e à umidade, pois geralmente, envolvem adições nucleofílicas mediadas por complexos metálicos. ${ }^{30}$ Na síntese do Remdesivir a obtenção do intermediário $C$-glicosilado ainda é bastante desafiadora, geralmente, necessitando de temperaturas reacionais muito baixas, apresentando baixos rendimentos, intermediários instáveis, além da formação de subprodutos tóxicos.

Em 1994, Klein e colaboradores reportaram pela primeira vez o preparo do $(3 R, 4 R, 5 R)$-2-(4-aminopirrolo[2,1- $f][1,2,4]$ triazin7-il)-3,4-bis(benziloxi)-5-((benziloxi)metil)tetraidrofuran-2-ol (27), que é intermediário-chave obtido por meio de um processo de $C$-glicosilação e utilizado no preparo do Remdesivir (Esquema 9) ${ }^{31} \mathrm{~A}$ estratégia de síntese se iniciou com um acoplamento do tipo Grignard entre o carboidrato 23 e o brometo de magnésio pirrol 24. Nessa abordagem, observou-se uma mistura de produtos $\mathrm{C}$ - e $\mathrm{N}$-glicosilados, resultando em uma baixa seletividade para a reação. Na sequência, a construção do núcleo pirrolo[2,1-f][1,2,4]triazin-4-amina foi realizada de maneira análoga à já descrita anteriormente pelo mesmo grupo de pesquisa. ${ }^{21}$ Nesse protocolo sintético, o intermediário 27 foi obtido em apenas 3\% de rendimento global utilizando 3 etapas, sendo duas delas one-pot, já que muitos dos intermediários formados sofriam degradação durante o processo de purificação.

Recentemente, a empresa Gilead Sciences reivindicou, por meio de patentes, algumas metodologias para a obtenção do intermediário 27 (Tabela 1). ${ }^{32-34} \mathrm{~A}$ metodologia para a formação desse produto partiu da base bromada 19 e da lactona derivada da ribose $\mathbf{2 8}$, utilizando-se ainda TMSCl como grupo protetor da amina e BuLi como agente de acoplamento. Nesse protocolo, foi necessária a utilização de baixas temperaturas $\left(-78^{\circ} \mathrm{C}\right)$ e foi possível obter um rendimento baixo $(25 \%)$ da mistura de anômeros de 27 (Tabela 1 - entrada 1).

Em 2012, um grupo de pesquisadores, publicaram uma inovação na síntese do produto $27 .{ }^{35}$ Nessa proposta foi avaliada a utilização do grupo protetor 1,2-bis-(clorodimetilsilil)etano (Tabela 1 - entrada 3), levando a uma melhora considerável no rendimento (60\%) quando comparado às outras metodologias descritas ou à reação na ausência de grupo protetor (Tabela 1 - entrada 2).

Alguns anos depois, uma nova patente depositada pela Gilead Sciences forneceu inovações em várias etapas da síntese do Remdesivir. No que tange à etapa de glicosilação utilizou-se a base iodada 20 e a lactona 28 na presença de cloreto de isopropilmagnésio ( $i \mathrm{PrMgCl})$ associado a ácidos de Lewis ou na presença de um complexo de acoplamento baseado em magnésio-lítio (cloreto de iso-propil magnésio-lítio) (Esquema 10). ${ }^{36}$ Com essas modificações foi possível realizar a síntese em temperaturas mais amenas (entre $0 \mathrm{e}$ $-20^{\circ} \mathrm{C}$ ), evitando temperaturas extremas de $-78^{\circ} \mathrm{C}$. Merece destaque também a possibilidade de uso de uma diversidade de ácidos de Lewis para realizar essa transformação, como $\mathrm{LaCl}_{3}-2 \mathrm{LiCl}, \mathrm{CeCl}_{3}$, $\mathrm{YCl}_{3}$ e $\mathrm{NdCl}_{3}$. 
<smiles>OC1O[C@H](COCc2ccccc2)[C@@H](O[Ga])[C@@H]1Oc1cccn1Br</smiles>

(23)
1) $\mathrm{CH}_{2} \mathrm{Cl}_{2}, 0^{\circ} \mathrm{C}, 1 \mathrm{~h}$

2) $\mathrm{CF}_{3} \mathrm{COOH}$, t.a., 3) $\mathrm{POCl}_{3}(1.8$ eq.) DMF, $0{ }^{\circ} \mathrm{C}$<smiles>[B]OC[C@H]1OC(O)(c2ccc(C=O)[nH]2)[C@H](Br)[C@@H]1OCc1ccccc1</smiles>

(25) $26 \%$<smiles>Nc1ncnn2c(C3(O)O[C@H](COc4ccccc4)[C@@H](O)[C@H]3O)ccc12</smiles>

Acetato de formamidina (10 eq.)

DMA, $140^{\circ} \mathrm{C}, 1,5 \mathrm{~h}$

1) O-mesitilenosulfonilhidroxialamina (1,1 eq), $\mathrm{NaH}$ (2 eq.), THF, $0^{\circ} \mathrm{C}, 0,75 \mathrm{~h}$ 2) $\mathrm{HOSA}(3,5$ eq.), $\mathrm{KOH}$ Dioxano/ $\mathrm{H}_{2} \mathrm{O}, 2 \mathrm{~h}$

(27) $45 \%$<smiles>Nn1c(C=O)ccc1C1(O)O[C@H](COBr)[C@@H](O)[C@H]1Br</smiles>

(26) $27 \%$

Esquema 9. Rota sintética de Klein e colaboradores para obtenção do C- nucleosídeo 27

Tabela 1. Protocolos sintéticos desenvolvidos pela Gilead Sciences para obtenção do $C$-nucleosídeo 27

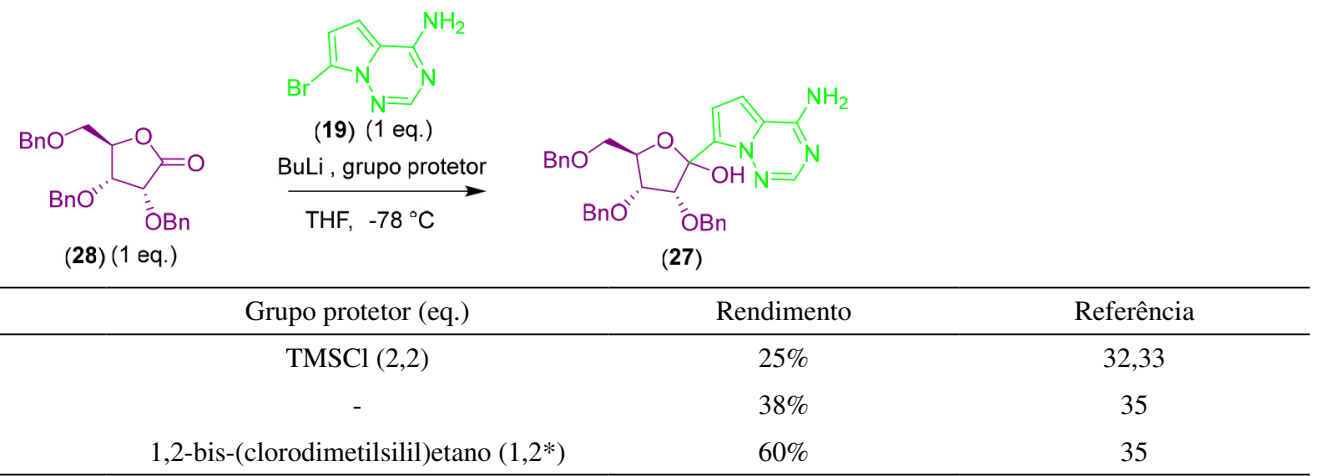

*Também requer o uso de $\mathrm{NaH}$ (2,2 eq.).<smiles>O=C1OC(COCc2ccccc2)[C@H](O)[C@H]1Br</smiles>

(28)<smiles>Nc1ncnn2c(I)ccc12</smiles>

(20)

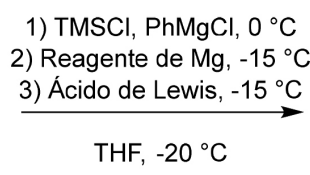

THF, $-20^{\circ} \mathrm{C}$<smiles>Nc1ncnn2c(C3(O)O[C@H](COCc4ccccc4)[C@@H](Br)[C@H]3OCc3ccccc3)ccc12</smiles>

(27)

Reagente de $\mathrm{Mg}=i \mathrm{PrMgCl}$ ou $\mathrm{PrMg}-\mathrm{LiCl}$

Ácido de Lewis $=\mathrm{LaCl}_{3}-2 \mathrm{LiCl}, \mathrm{CeCl}_{3}, \mathrm{YCl}_{3}$ ou $\mathrm{NdCl}_{3}$

Esquema 10. Metodologia sintética desenvolvida para a etapa de glicosilação

Os detalhes experimentais, como equivalência dos reagentes e rendimentos de cada etapa, não haviam sidos descritos nessa patente. Contudo, no mesmo ano, Bavari e colaboradores reportaram os detalhes experimentais de uma síntese bastante similar (Esquema 11) ${ }^{37}$ Embora o rendimento isolado para a etapa de $C$-glicosilação $(41,5 \%)$ tenha sido inferior aos $60 \%$ obtidos por outra metodologia anteriormente descrita, as condições reacionais utilizadas, especialmente no que tange à temperatura $\left(-20^{\circ} \mathrm{C}\right)$, foram consideravelmente mais amenas.

Recentemente, Qin e colaboradores, reportaram a utilização da diisopropilamina como aditivo com a finalidade de aprimorar a metodologia de síntese de 27 (Esquema 12). ${ }^{38}$ Os autores obtiveram sucesso na síntese de larga escala, obtendo os anômeros do intermediário $C$-glicosilado com rendimento de $74 \%$ (escala de $10 \mathrm{~g}$ da base 19) e 64\% (escala de $180 \mathrm{~g}$ da base 19). Uma das principais vantagens dessa metodologia foi que, diferentemente das metodologias até então descritas, a purificação do composto foi realizada por recristalização, não sendo necessária a purificação por cromatografia em coluna.

Em termos mecanísticos, os autores sugeriram que a amina secundária poderia atuar facilitando a proteção da base 19 através da interação com o intermediário 30. Além disso, a amina poderia

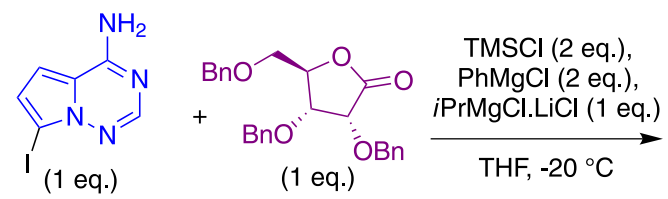

(20)<smiles>Nc1ncnn2c(C3(O)O[C@H](COCc4ccccc4)[C@@H](Br)[C@@H]3Br)ccc12</smiles>

(27) $41,5 \%$ (r.d. $1: 1$ )

Esquema 11. Metodologia sintética descrita para a etapa de glicosilação 


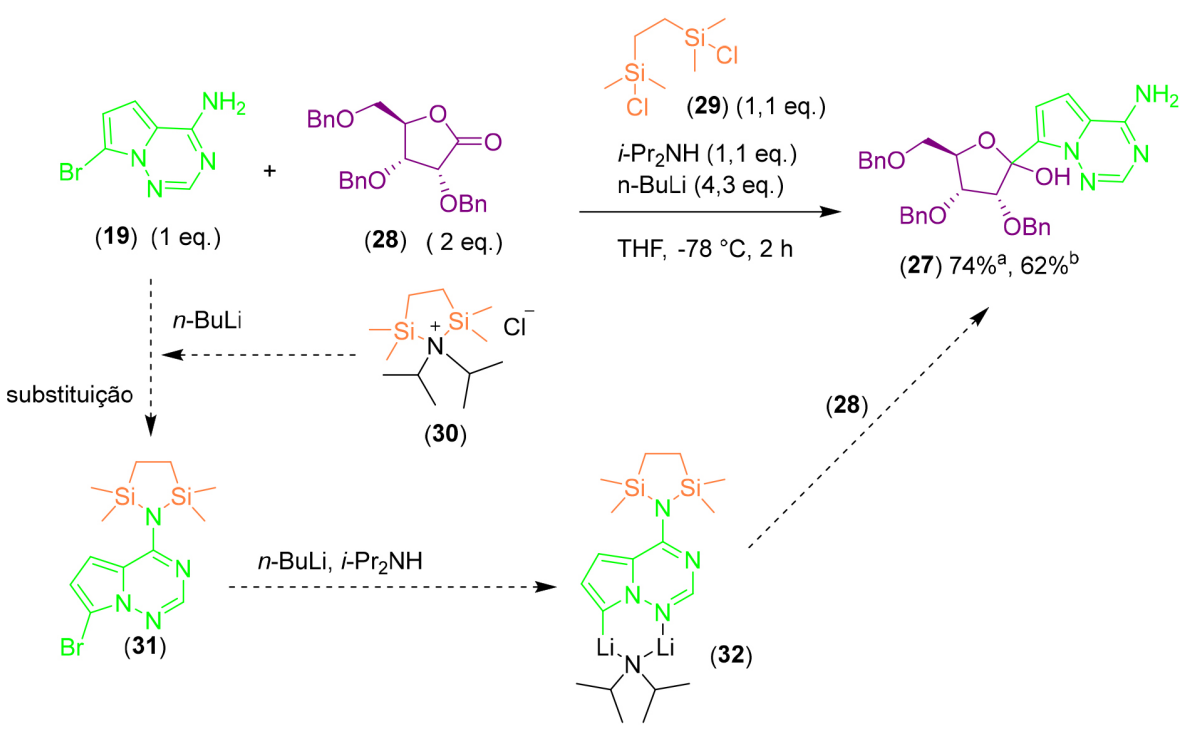

Escala de sintese utilizando: a) $10 \mathrm{~g}$ da base 19 ; b) $180 \mathrm{~g}$ da base 19

Esquema 12. Rota sintética de Qin e colaboradores para obtenção do C-nucleosídeo 27 e hipótese sobre a atuação do aditivo diisopropilamina

ainda contribuir estabilizando o intermediário de lítio 32, auxiliando assim a formação do produto desejado 27 . Vale ressaltar que, durante a etapa de avaliação do aditivo, os autores mencionaram que aminas secundárias volumosas apresentavam um melhor desempenho que as não volumosas e aminas terciárias não apresentavam um bom desempenho como aditivo.

Em 2020, Kappe e colaboradores reportaram a utilização de uma metodologia em fluxo contínuo utilizando a estratégia de troca metalhalogênio para a síntese de 27 (Esquema 13). ${ }^{28}$ A grande inovação dessa proposta é evitar a exposição desnecessária de intermediários instáveis e minimizar os longos períodos de adição de reagentes, mandatórios para reações altamente exotérmicas em sistema de batelada. Nesse sentido, em cada etapa de adição dos reagentes foi quantificada a energia associada e, com isso, foi possível estimar as condições necessárias para o desenvolvimento dessa reação em grande escala, levando a um rendimento de $47 \%$ e tolerando o preparo de até $51,8 \mathrm{mmol} \mathrm{h}^{-1}$ do composto desejado.

No ano seguinte, o grupo de Kappe propôs uma metodologia utilizando os princípios da química flash para a obtenção do produto $C$-glicosilado 27 em $60 \%$ de rendimento. ${ }^{39}$ Os princípios da química flash se concentram em reações rápidas, realizadas em questões de segundos, usando um sistema de fluxo para a obtenção de intermediários que, geralmente, não são obtidos com sucesso nas vias clássicas de reações. ${ }^{40}$ Nessa nova metodologia, foi utilizado um sistema de fluxo contínuo, permitindo o uso de uma temperatura de reação relativamente amena $\left(-30^{\circ} \mathrm{C}\right)$ quando comparada à usual em metodologias de $C$-glicosilação, com um tempo de residência de apenas 8 segundos e na presença de LDA para evitar a formação de sólidos (Esquema 14). Esse fluxo ainda foi mantido durante $2 \mathrm{~h}$ e com uma produção de $16,9 \mathrm{~g}$, o que corresponde a um rendimento de $10,4 \mathrm{~kg} \mathrm{~L}^{-1} \mathrm{~h}^{-1}$.

Em sistema de batelada, a velocidade de adição do $n$-BuLi é mandatória para reprodutibilidade do rendimento, uma vez que pode levar à transferência inadequada de calor em microambientes isolados (uma vez que a reação é exotérmica). Nesse estudo, demonstrou-se que um sistema de fluxo é capaz de atenuar esse tipo de problema, evitando a decomposição do intermediário litiado desejado. Além disso, o organolítio empregado precisa ter um alto caráter nucleofílico de maneira a evitar a abstração do hidrogênio ácido da lactona e favorecer de fato a $C$-glicosilação.

No mesmo ano, Shen e colaboradores descreveram uma nova metodologia para $C$-glicosilação capaz de minimizar a formação de subprodutos. ${ }^{41}$ A estratégia desse estudo consistiu no emprego de uma amida de Weinreb como intermediário-chave, evitando a possibilidade de dupla adição da base $\mathbf{2 7}$ ao derivado da ribose $\mathbf{2 8}$. Foram descritas duas propostas: a primeira em 4 etapas fornecendo o produto 27 em $65 \%$ de rendimento (Esquema 15A) e a segunda em apenas 2 etapas, bastante promissora ( $60 \%$ de rendimento), mas que necessita de tempos reacionais mais longos (Esquema 15B). As principais vantagens dessas propostas consistem na possibilidade de

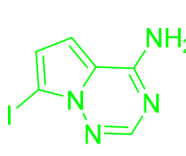

(20) $(1$ eq.)

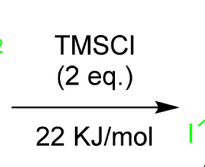

$\mathrm{Cl}^{-}$

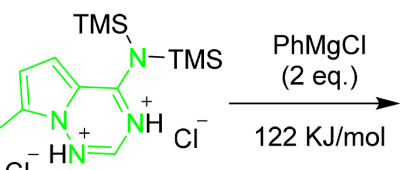

(33)<smiles>Nc1ncnn2c(C3(O)O[C@H](COCc4ccccc4)[C@@H](OCc4ccccc4)[C@H]3OCc3ccccc3)ccc12</smiles>

(27)

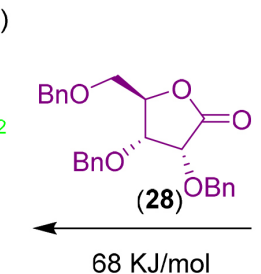<smiles>CN(c1ncnn2c(I)ccc12)S(C)(=O)=O</smiles>

(34)

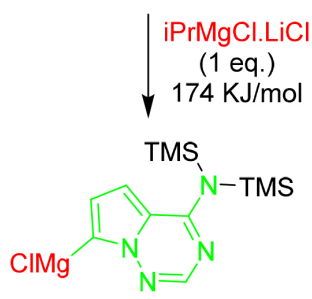

(35)

Esquema 13. Análise calorimétrica da adição de cada reagente na etapa de C-glicosilação visando a obtenção do C- nucleosídeo 27 


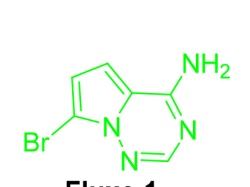

Fluxo 1

(19) $0,1 \mathrm{M}^{\mathrm{a}}$ (1 eq.)
Fluxo 2 - (29) (1,0 $M^{a}-0,6$ eq. $)$

Fluxo 3 - LDA (1,0 $\mathrm{M}^{\mathrm{ab}}-2$ eq. $)$

Fluxo 4 - $n$ BuLi (1,6 $\mathrm{M}^{\mathrm{b}}-3$ eq.)

Fluxo 5 - ribolactona 28 ( $1 \mathrm{M}^{\mathrm{a}}-1,8$ eq. $)$

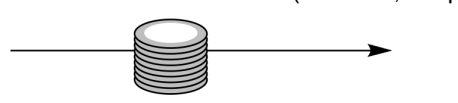

$-30^{\circ} \mathrm{C}$

elaboração com $\mathrm{NH}_{4} \mathrm{Cl}$ (aq)

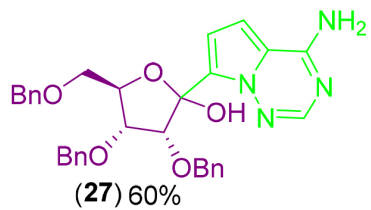

(27) $60 \%$

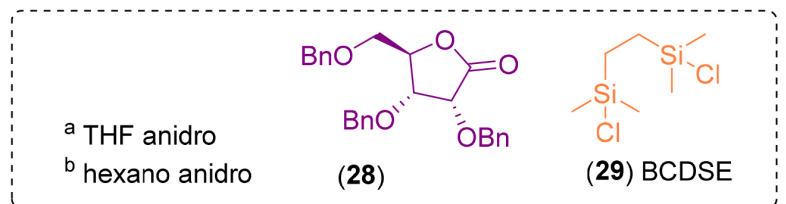

Esquema 14. Síntese do C-nucleosídeo 27 utilizando um sistema de fluxo

purificação do produto desejado através de recristalização em metil terc-butil éter (MTBE) e na substituição do $\mathrm{PhMgCl}$ por $\mathrm{MeMgBr}$, evitando a formação de benzeno como subproduto.

Embora várias modificações na etapa de $C$-glicosilação tenham sido propostas recentemente, possibilitando uma considerável melhora na eficiência das reações e na minimização da formação subprodutos, a maioria das metodologias ainda utiliza reagentes bastante sensíveis e que requerem um tratamento anidro, temperaturas baixas, necessidade de manipulação de grupos protetores que podem contribuir com dificuldades operacionais e também no aumento no custo do processo como um todo.

\section{Etapa de cianação}

As reações de cianação constituem uma importante e desafiadora etapa durante a síntese do Remdesivir, necessitando de cuidados devido à elevada toxicidade do cianeto de hidrogênio, que pode ser utilizado diretamente ou gerado in situ a partir de outros reagentes como TMSCN, cianoformato de etila, cianato de acetila e acetona de cianoidrina. ${ }^{42}$ Essas reações podem ser divididas em duas categorias: a adição nucleofílica a compostos polarizados, ou cianação conjugada em carbonilas $\alpha, \beta$-insaturadas. ${ }^{43} \mathrm{Na}$ síntese do Remdesivir, o intermediário de cianação $\mathbf{4 0}$ geralmente é planejado segundo a primeira categoria, normalmente utilizando o TMSCN como fonte de grupo ciano. Nessas reações já foram avaliados diversos ácidos de Lewis como catalisadores, várias faixas de temperatura, equivalência de reagentes e ordem de adição e todos esses quesitos se mostraram bastante importantes na eficiência da reação.

Recentemente, a empresa Gilead Sciences reivindicou através de uma série de patentes, metodologias para vários intermediários avançados do Remdesivir, incluindo a obtenção do produto de cianação $\mathbf{4 0}$ através do tratamento do composto 27 com um doador de grupo ciano (TMSCN) em diclorometano. ${ }^{32-34}$ Para esse protocolo, foram avaliados como catalisadores dois ácidos de Lewis: o $\mathrm{BF}_{3}-\mathrm{Et}_{2} \mathrm{O}$ e o TMSOTf (Tabela 2 - Entradas 1 e 2), fornecendo rendimentos de $37 \%$ e de $90 \%$, respectivamente. Merece destaque como principal

A)

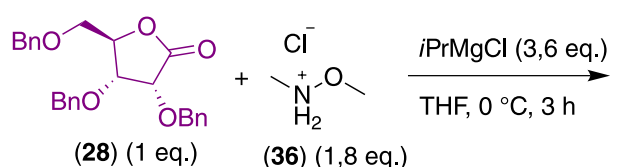

(28) (1 eq.)

(36) $(1,8$ eq. $)$

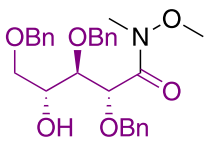

(37) $100 \%$

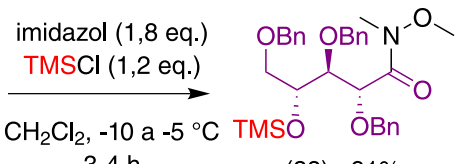

(38) $91 \%$

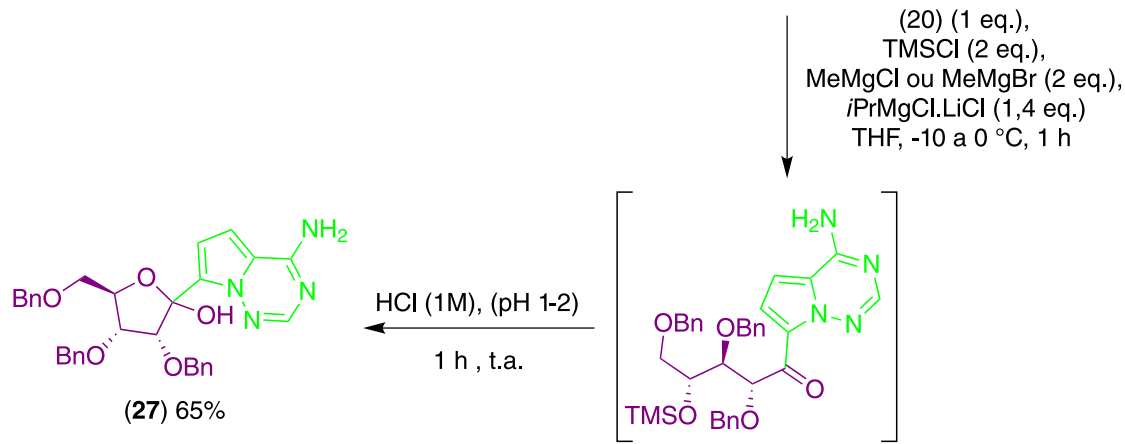

B)

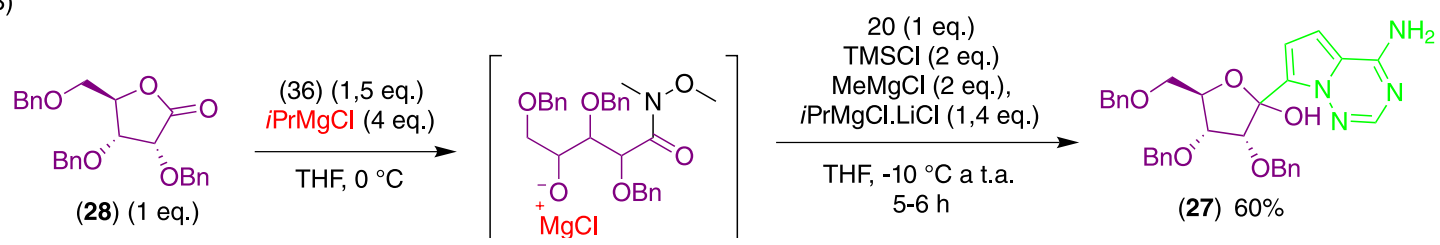

Esquema 15. Síntese do C-nucleosídeo 27 utilizando uma amida de Weinreb como intermediário 
Tabela 2. Condições sintéticas desenvolvidas pela Gilead Sciences para obtenção de $\mathbf{4 0}$

\begin{tabular}{|c|c|c|c|c|c|c|}
\hline Entrada & TMSCN (eq.) & Ácido de Lewis (eq.) & Temperatura $\left({ }^{\circ} \mathrm{C}\right)$ & Tempo & Rendimento $(\beta / \alpha)$ & Referência \\
\hline 1 & 5,5 & $\mathrm{BF}_{3} \cdot \mathrm{Et}_{2} \mathrm{O}(7,9)$ & 0 - t.a. & nd & $37 \%(-)$ & 32,33 \\
\hline 2 & 4,6 & TMSOTf (11) & 0 - t.a. & nd & $90 \%(-)$ & 32 \\
\hline 3 & 4 & TMSOTf (3) & 0 & nd & $76 \%(57 / 43)$ & 35 \\
\hline 4 & 4 & TMSOTf (3) & -78 & $5 \mathrm{~h}$ & $65 \%(89 / 11)$ & 35 \\
\hline 5 & 4 & $\mathrm{BF}_{3} \cdot \mathrm{Et}_{2} \mathrm{O}(3)$ & -78 & $5 \mathrm{~h}$ & $58 \%(85 / 15)$ & 35 \\
\hline
\end{tabular}

problema nesses protocolos o uso de grande excesso dos agentes de cianação.

Em 2012, Kim e colaboradores publicaram uma nova alternativa para preparo do composto $\mathbf{4 0}$ empregando como ácidos de Lewis o TMSOTf e o $\mathrm{BF}_{3}-\mathrm{Et}_{2} \mathrm{O} \cdot{ }^{35} \mathrm{No}$ geral, foi verificado que o uso de baixas temperaturas $\left(-78{ }^{\circ} \mathrm{C}\right)$ leva a uma seletividade para o anômero $\beta$ (Tabela 2 - entradas 4 e 5). A formação do complexo 41 (Figura 2) foi proposto como responsável por levar à formação majoritária do produto $\beta$, devido à coordenação do silício ao oxigênio favorecer o ataque nucleofílico à face $S i$ da carbonila.

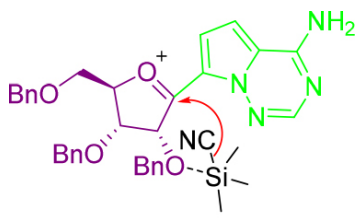

(41)

Figura 2. Modo de aproximação proposto para a etapa de cianação

Recentemente, uma patente forneceu inovações importantes na etapa de cianação (Esquema 16). ${ }^{36}$ Nessa etapa, houve a substituição do solvente DCM por THF, além do uso de ácido trifluoracético (TFA) como ácido de Brønsted. Embora tenha sido descrito que essa metodologia possa ser efetuada tanto em batelada quanto em sistema de fluxo contínuo, detalhes experimentais como a equivalência dos reagentes e os rendimentos não foram descritos.

Em 2016, Bavari e colaboradores apresentaram detalhes experimentais para uma metodologia bastante similar (Esquema 17). ${ }^{37}$ A metodologia de cianação forneceu o produto desejado em ótimo rendimento $(85 \%)$ e uma razão diasteroisomérica $>95: 5$. Embora<smiles>Nc1ncnn2c(C3(O)O[C@H](COCc4ccccc4)[C@@H](Br)[C@H]3Br)ccc12</smiles>
(27) (40)

Esquema 16. Metodologia sintética para a cianação do composto 27 os resultados sejam excelentes, a principal dificuldade operacional desse protocolo em grande escala consiste no uso de temperaturas reacionais muito baixas $\left(-78^{\circ} \mathrm{C}\right)$.

Em 2020, Heumann e colaboradores utilizaram a química em fluxo contínuo como estratégia tecnológica para a obtenção do produto de cianação $\mathbf{4 0} .{ }^{44}$ Utilizando o ácido trifluoracético como ácido de Brønsted e uma temperatura reacional mais amena $\left(-30^{\circ} \mathrm{C}\right)$, foi possível o acesso ao produto desejado em bons rendimentos e diasterosseletividades (88,6\% e 93:7 r.d., respectivamente) (Esquema $18 \mathrm{~A})$. No entanto, o aumento da escala de reação em 330 vezes levou a uma considerável queda no rendimento $(69,2 \%)$.

Na sequência, o processo em fluxo contínuo foi avaliado visando a evitar a exposição dos reagentes a tempos prolongados de reação e impedir a decomposição dos reagentes de partida. No sistema de fluxo, a reação foi conduzida com sucesso em uma escala de até 100 gramas, não sendo necessário, neste caso, o uso de TFA (Esquema 18B), o que foi atribuído à formação in situ de TfOH pela hidrólise do TMSOTf por traços de água. Contudo, esse efeito não se manteve significativo em um novo escalonamento para $250 \mathrm{~kg}$ de 27 (Esquema 18C), sendo necessária a reintrodução do TFA e uma sutil alteração na temperatura $\left(-40{ }^{\circ} \mathrm{C}\right)$, resultando no produto desejado 40 em $78 \%$ de rendimento e 94:6 r.d.

No geral, embora a etapa de cianação do intermediário do Remdesivir já tenha recebido inúmeras modificações metodológicas, com consideráveis melhorias especialmente no que diz respeito à eficiência da reação, ainda há a necessidade de uso de ácidos fortes, de uso de grande excesso dos reagentes envolvidos na cianação e de temperaturas reacionais consideravelmente baixas.

\section{Etapa de fosforamidação assimétrica}

Além das frações descritas até aqui, uma última porção fundamental na estrutura do Remdesivir é o grupo da fração fosforoamidato quiral contendo uma cadeira lateral derivada do éster 2-etilbutílico do aminoácido L-alanina. Recentemente, novas estratégias foram descritas para a etapa de fosforamidação assimétrica da unidade nucleosídica.

Na primeira geração de síntese descrita pela Gilead Sciences, a etapa de fosforamidação se dá entre uma mistura diastereoisomérica<smiles>Nc1ncnn2c(C3(O)O[C@H](COCc4ccccc4)[C@@H](OCc4ccccc4)[C@H]3OCc3ccccc3)ccc12</smiles>

(27)

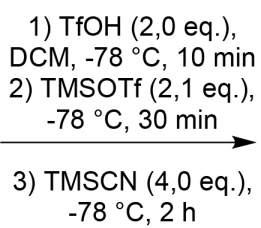

$-78^{\circ} \mathrm{C}, 2 \mathrm{~h}$

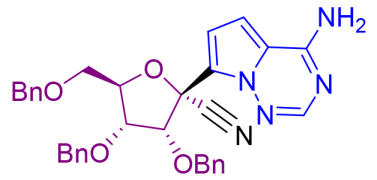

(40) $85 \%$ (r.d. $>95: 5)$

Esquema 17. Proposta sintética para preparo do produto de cianação 40 
A) Metodologia em batelada

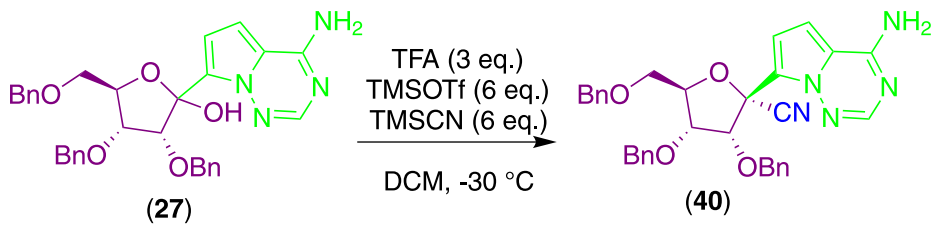

Escala de $0,2 \mathrm{~g}$ de $27: 88,6 \%$ (r.d. $=93: 7)$

Escala de $66 \mathrm{~g}$ de $27: 69,2 \%$ (r.d. $=90: 10$ )

B) Metodologia em fluxo - escala de gramas $(100 \mathrm{~g})$

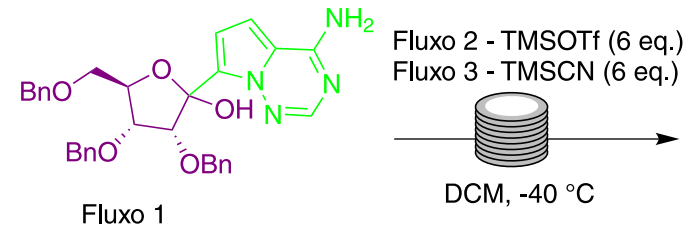

(27)

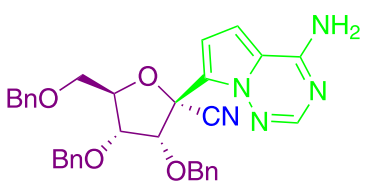

$88 \%$ (r.d. $=91: 9$ )

C) Metodologia em fluxo - escala de quilogramas (250 kg de 27)

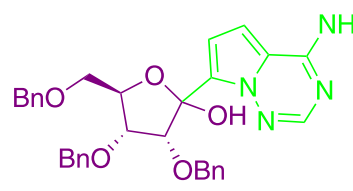

Fluxo 1

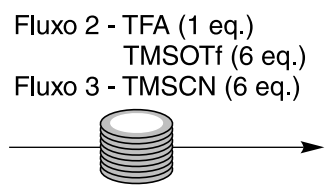

DCM, $-30^{\circ} \mathrm{C}$

(27)

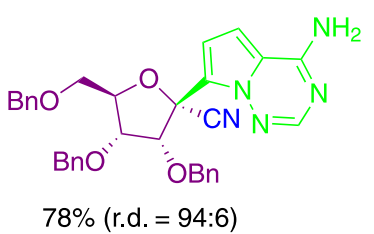

(40)

Esquema 18. Metodologias para a obtenção do produto de cianação 40

do cloridrato de fosforoamidoíla 43 e a unidade nucleosídica desprotegida 42, na presença de $N$-metilimidazol (NMI) e fosfato de trimetila anidro, fornecendo a mistura diastereoisomérica $\mathbf{4 4}$ contendo o Remdesivir e seu estereoisomero (r.d. 1:1) em apenas $21 \%$ de rendimento, sendo ainda necessária sua posterior purificação por cromatografia líquida de alta eficiência (CLAE) (Esquema 19). ${ }^{27}$

Já na segunda proposta de síntese foi descrita uma melhora significativa na etapa de fosforamidação, ao utilizar a unidade fosforilada $p$-nitrofenolada diastereomericamente pura 45 no acoplamento com o derivado nucleosídico 42 , mediado por $(i-\mathrm{Pr})_{2} \mathrm{NEt}$ e $\mathrm{MgCl}_{2}$, em acetonitrila, o qual ocorre com inversão da estereoquímica do átomo de fósforo, levando ao intermediário $46 .{ }^{45}$ Após a etapa final de desproteção do grupo isopropilideno e purificação por coluna flash, Remdesivir foi isolado em $69 \%$ de rendimento. Como principal vantagem desse protocolo destaca-se a eliminação da separação por CLAE, uma vez que o diasteroisômero puro do precursor $\mathbf{4 5}$ foi previamente preparado e isolado via cristalização seletiva em éter diisopropílico da mistura racêmica precursora (39\% de rendimento). ${ }^{46}$ Por outro lado, etapas adicionais de proteção das hidroxilas através de um acetonídeo e sua posterior desproteção foram necessárias, levando a um aumento no número de etapas.

No que se refere às novas estratégias de fosforamidação, todas datam de 2020 e 2021 e envolvem estratégias modernas, como catálise assimétrica e processos one-pot. Em 2020, Zhang e colaboradores descreveram a primeira síntese assimétrica catalítica do Remdesivir (Esquema 20), empregando o catalisador imidazólico bicíclico quiral

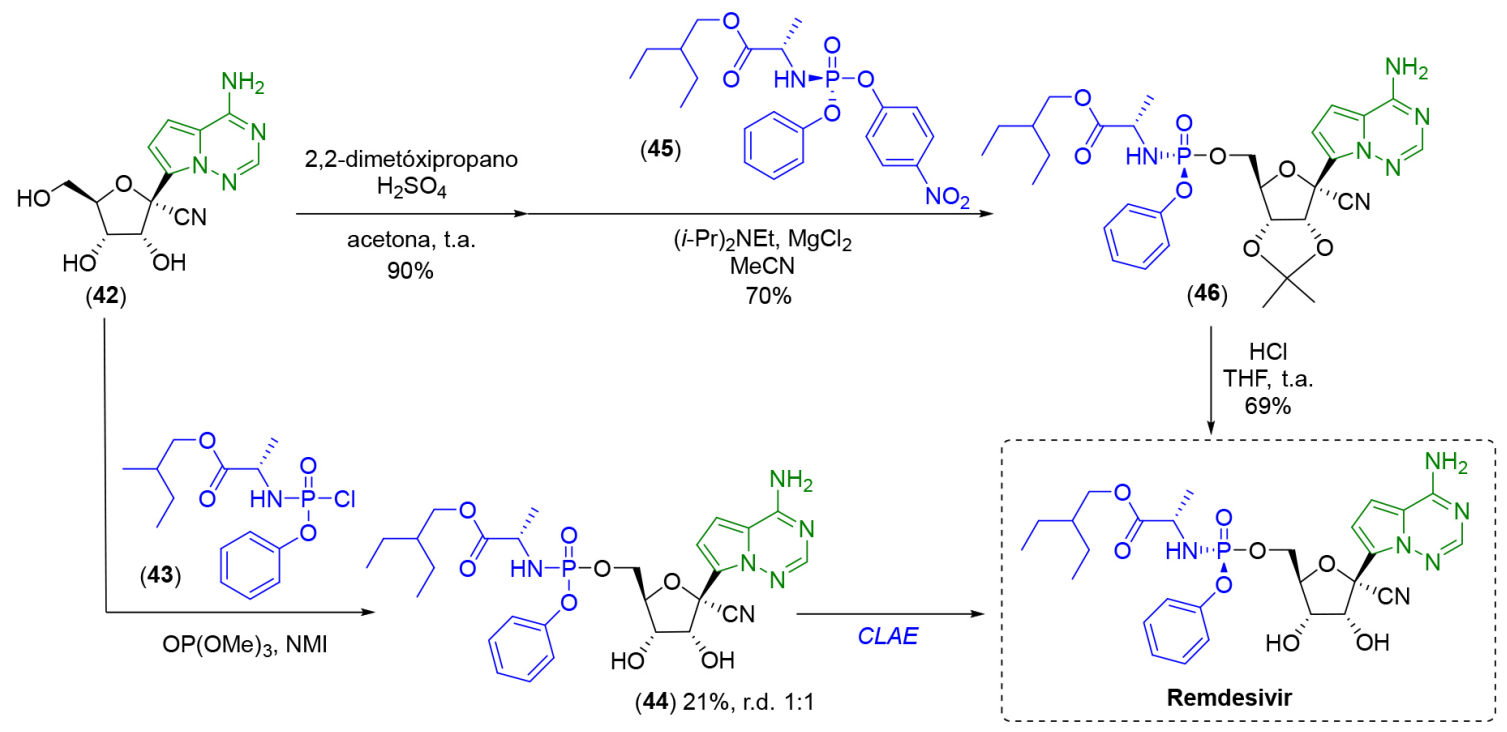

Esquema 19. Etapa de fosforamidação da primeira e segunda gerações de síntese do Remdesivir 
adamantil-carbamato $\mathbf{4 8}$ em uma transformação cinético dinâmica assimétrica. ${ }^{47}$ Esse acoplamento eficiente se deu entre o racemato do cloridrato de fosforoamidoíla 43 e o derivado nucleosídico protegido 47 , levando ao produto 46 em até $96 \%$ de conversão e razão diasteroisomérica de 22:1. O potencial para aplicação industrial dessa nova metodologia de fosforamidação foi demonstrado em um experimento partindo de $10,0 \mathrm{~g}$ do substrato 47 , fornecendo o intermediário 46 em $89 \%$ de rendimento e razão diastereoisomérica > 99:1 e o Remdesivir em 73\% de rendimento, após etapa de remoção do grupo isopropilideno.

Uma segunda abordagem de fosforamidação estereosseletiva bastante similar também foi descrita por outro grupo de pesquisa, utilizando o catalisador imidazólico bicíclico quiral 49 (Esquema 20). ${ }^{48}$ A inovação dessa proposta pode ser atribuída ao emprego de um processo one-pot, potencialmente atrativo do ponto de vista industrial, compreendendo as etapas de fosforamidação e remoção do grupo protetor da unidade nucleosídica e levando ao Remdesivir em $70 \%$ de rendimento e 99,3:0,7 r.d.

Recentemente, Shen e colaboradores utilizaram a $\mathrm{N}, \mathrm{N}$ dimetilformamida dimetil acetal (50) como grupo protetor da unidade nucleosídica a ser acoplada com a porção fosforoamidato quiral (Esquema 21). ${ }^{49}$ Os pesquisadores mostraram que a proposta sintética, desenvolvida originalmente para a síntese one-pot do antiviral Molnupiravir, pode ser aplicada também às etapas finais de síntese do Remdesivir. Assim, foi realizada a proteção das hidroxilas 2' e 3' de 42 com 50, seguida do acoplamento no mesmo frasco reacional da unidade nucleosídica $\mathbf{5 1}$ com a fosforoamida pentafluorada $\mathbf{5 2}$ e a remoção do grupo 2',3'-O-dimetilaminometileno pelo agente de desproteção $\mathrm{MeMgBr}$, levando ao intermediário 53 em 85\% de rendimento para as três etapas (Esquema 21). Finalmente, a desproteção do grupo amina foi realizada utilizando-se ácido acético em etanol, resultando no Remdesivir em $90 \%$ de rendimento. Esse trabalho é uma importante contribuição, em virtude da proposta inovadora de substituição do grupo protetor acetonídeo, da abordagem one-pot $\mathrm{e}$ do aumento do rendimento obtido.

As patentes depositadas por Tao e colaboradores descrevem a etapa de fosforamidação utilizando o derivado nucleosídico protegido com acetonídeo 47 e porções fosforoamida quirais contendo, respectivamente, pentafluorfenol (54) ou 4-trifluormetóxifenol (55), como grupos de saída (Esquema 22). ${ }^{50,51} \mathrm{O}$ método descrito sugere o uso de bases orgânicas fortemente impedidas como cloreto de terc-butilmagnésio $(t-\mathrm{BuMgCl})$ ou hexametilsililazida de sódio (NaHMDS) como agentes de desproteção na etapa de acoplamento e de condições ácidas típicas $(\mathrm{HCl}$ ou $\mathrm{AcOH})$ para desproteção do grupo isopropilideno na última etapa. Os inventores ressaltam que as propostas são adequadas para emprego em escala industrial e que a substituição do fosforoamidato quiral nitro-substituído $\mathbf{4 5}$ por qualquer uma das porções utilizadas nas referidas invenções reduz o risco de presença de impurezas genotóxicas. Por outro lado, os rendimentos não foram fornecidos, o que impossibilita uma comparação da eficiência desse método com os demais métodos descritos na literatura.

Em uma outra patente, Yihua e colaboradores descrevem a mesma sequência reacional representada no Esquema 22, utilizando a

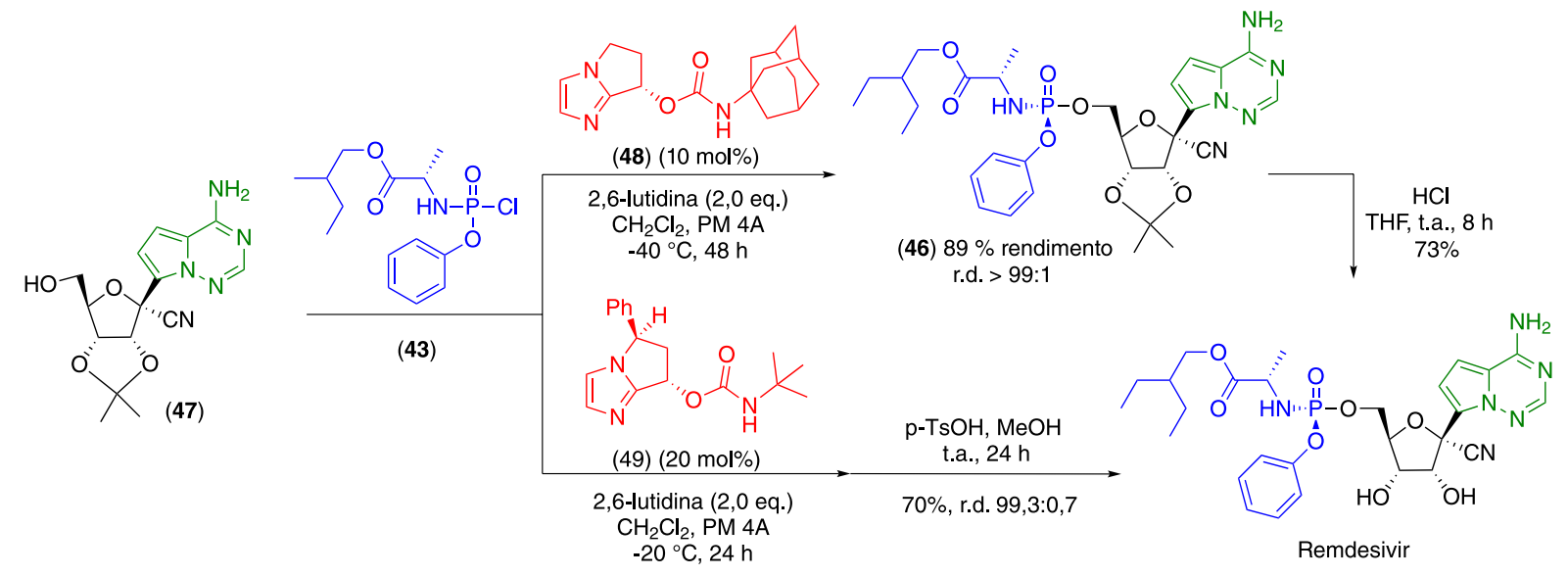

Esquema 20. Fosforamidação via catálise assimétrica em uma escala de 10,0 g de $\mathbf{4 7}$

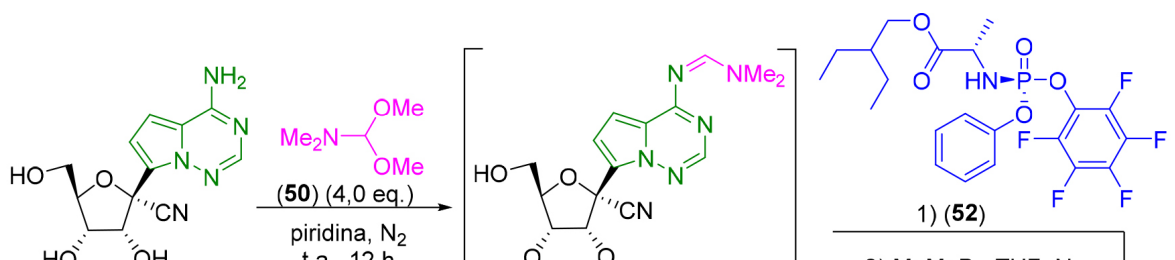

(42) t.a., $12 \mathrm{~h}$<smiles>CN(C)[Hg]</smiles>

2) $\mathrm{MeMgBr}, \mathrm{THF}, \mathrm{N}_{2}$ -15 a $0^{\circ} \mathrm{C}, 3 \mathrm{~h}$
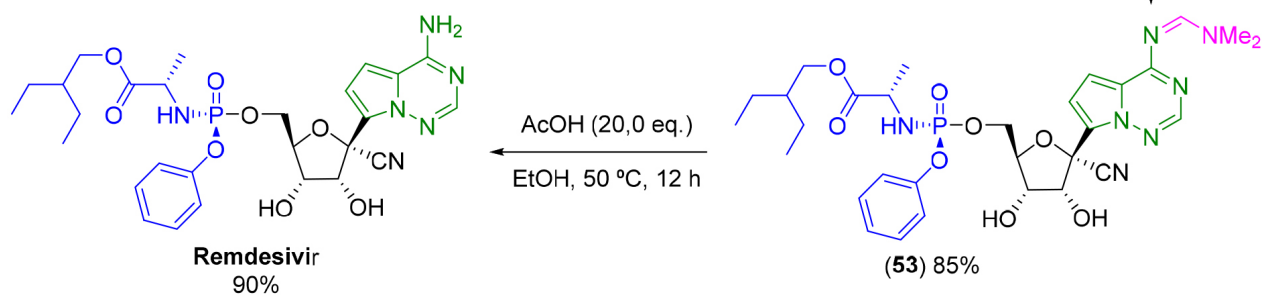

(53) $85 \%$

Esquema 21. Fosforamidação utilizando o grupo protetor 50 na síntese do Remdesivir 


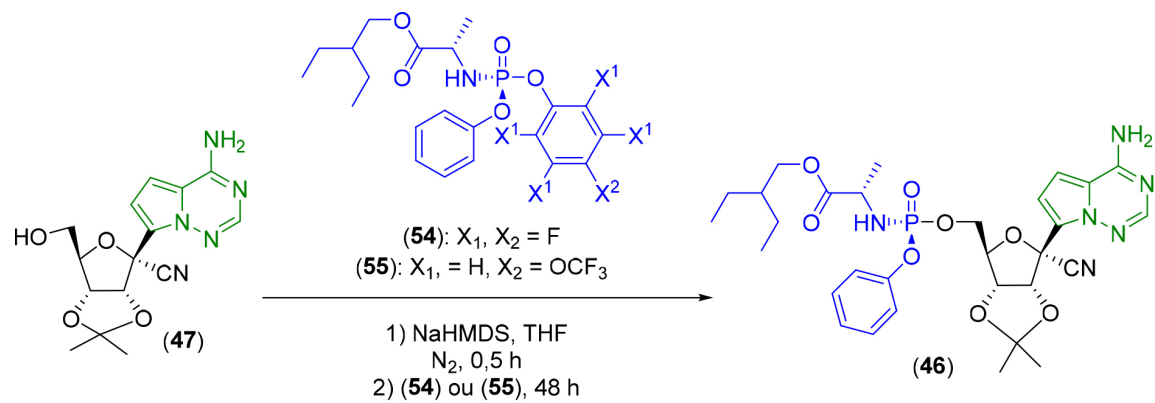

2) (54) ou (55), $48 \mathrm{~h}$

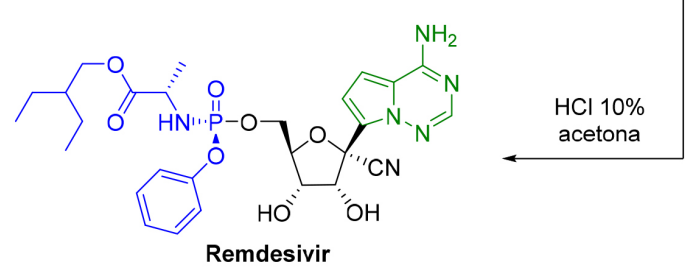

Esquema 22. Fosforamidação utilizando fosforoamidas contendo grupos pentafluorfenol ou 4-trifluormetoxifenol

fosforoamida quiral contendo pentafluorfenol 54, e um modo contínuo de operação sob condições microfluídicas em microreatores.$^{52}$ É sabido que a execução de reações químicas nessas condições se caracteriza como uma alternativa atrativa, quando comparada às condições em batelada e semi-batelada tradicionais, conferindo ao processo, um melhor controle da estequiometria, cinética e troca térmica da reação, além de facilitar o aumento da escala de produção. ${ }^{53}$ Assim, o rendimento descrito para a etapa de fosforamidação é de até 90,6\%, sendo 46 obtido em elevado grau de pureza (até 99,1\%), após extração líquido-líquido seguida de lavagem com éter de petróleo e filtração.

Benshun e colaboradores também descreveram a etapa de fosforamidação utilizando o derivado nucleosídico protegido com benzaldeído dimetilacetal 56 e a unidade fosforilada $p$-nitrofenolada 45 (Esquema 23). ${ }^{54} \mathrm{O}$ acoplamento se dá na presença de uma base como DIPEA, $N$-metilimidazol ou imidazol, em até $82 \%$ de rendimento após purificação por coluna cromatográfica. Após hidrólise do grupo protetor de 57 em meio ácido, Remdesivir é obtido em $84 \%$ de rendimento. Os autores sugerem que a substituição do grupo envolvido na proteção do sistema 2',3'-diol reduz o risco de formação de subprodutos e melhora o rendimento do processo quando comparado às rotas originais.

O mesmo grupo descreveu também o acoplamento entre a unidade nucleosídica desprotegida 42 e a porção fosforoamida quiral contendo $N$-hidroxisuccinimida como grupo de saída $\mathbf{5 8}$ na presença de uma base como trimetilamina ou trietilamina e de um ácido de Lewis (óxido ou brometo de magnésio, por exemplo), fornecendo o Remdesivir em rendimento de $78 \%$ (Esquema 24). ${ }^{55}$ Esse método de fosforamidação fornece o antiviral em elevado grau de pureza ( $>99 \%)$ diretamente após essa etapa, sem a necessidade de purificação por coluna cromatográfica. É importante destacar ainda que, uma vez que o acoplamento envolve o derivado nucleosídico desprotegido, a etapa de clivagem de grupo protetor é eliminada, reduzindo assim etapas adicionais do processo de produção.

\section{TENOFOVIR}

O análogo de nucleosídeo Tenofovir (2), comercializado na forma do pró-fármaco fumarato de Tenofovir desoproxila (59), é um antiviral amplamente utilizado como um inibidor da transcriptase reversa do vírus da imunodeficiência humana (HIV), tendo sido projetado para melhorar a absorção e a permeabilidade celular (Figura 3). ${ }^{1}$ Esse fármaco, também empregado para o tratamento da hepatite $\mathrm{B}$, pertence à classe dos fosfonatos de aciclonucleosídeos e é comercializado como Viread ${ }^{\circledR}$ pela Gilead Sciences. ${ }^{2}$ Recentemente ele tem sido amplamente investigado como possível alternativa para o tratamento da Covid-19. ${ }^{8,9,56-58}$

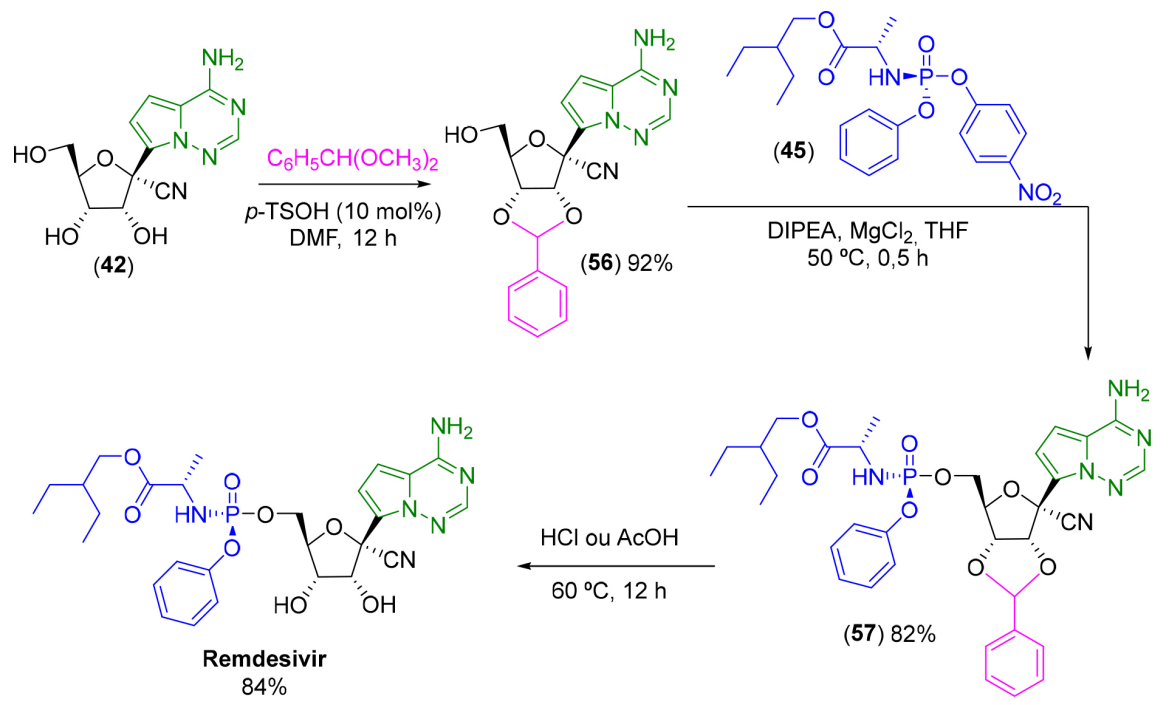

Esquema 23. Fosforamidação utilizando unidade nucleosídica protegida com benzaldeído dimetilacetal 


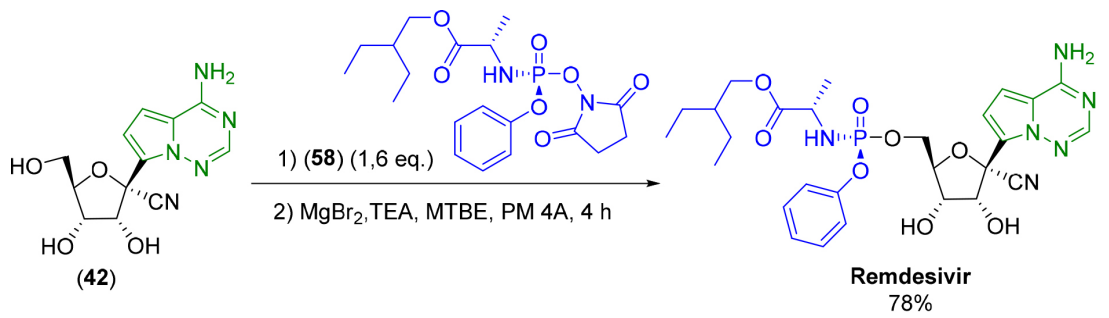

Esquema 24. Fosforamidação utilizando porção fosforoamida contendo N-hidroxisuccinimida<smiles>CC(Cn1cnc2c(N)ncnc21)OCP(=O)(O)O</smiles>

(Tenofovir - 2)<smiles>[M]C(Cn1cnc2c(N)ncnc21)OCP(=O)(OCOC(=O)OC(C)C)OCOC(=O)OC(C)C</smiles>

Figura 3. Estruturas químicas do Tenofovir e do fumarato de Tenofovir desoproxila

Ao longo dos anos, diferentes estratégias sintéticas já foram descritas para a preparação e purificação do Tenofovir, precursor sintético do seu pró-farmaco 59. ${ }^{59}$ As primeiras rotas de síntese comerciais, incluindo a descrita pela Gilead Sciences, comumente envolvem o uso do núcleo amplamente disponível comercialmente adenina (60), de um carbonato quiral $\mathbf{6 1}$ para sua $N$-alquilação e de uma etapa para a introdução do fosfonato 62 (Esquema 25).$^{60,61}$ Já a inserção dos dois grupamentos ésteres de carbonato de metila ao Tenofovir, a qual leva à obtenção do pró-fármaco comercial, geralmente se dá pelo uso de cloreto de metilisopropilcarbonato.

A rota de produção comercial do pró-fármaco $\mathbf{5 9}$ consiste em um processo de três estágios e quatro etapas reacionais sequenciais<smiles>[R]OP(=O)(O)CO[C@@H](C)Cn1cnc2c(N)ncnc21</smiles>

(Tenofovir)

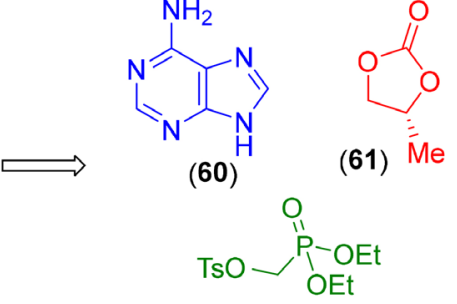

(62)
Esquema 25. Análise retrosintética das propostas mais usuais para preparação do Tenofovir a partir da adenina (60) (Esquema 26). ${ }^{61-63} \mathrm{~A}$ instalação do único estereocentro se dá já na primeira etapa, por meio da $N$-alquilação da adenina com carbonato de $(R)$-propileno 61. A introdução da ligação fosfonato ao intermediário 63 é realizada usando fosfonato de dietil(tosiloxi)metila (62), via $O$-alquilação mediada por base, fornecendo o intermediário éster fosfonato 64. A seguir, a hidrólise dos grupamentos ésteres dietil fosfonatos por ação de TMSBr, fornece o hidrato de Tenofovir (65), o qual é então esterificado com cloreto de metilisopropilcarbonato, fornecendo o composto $\mathbf{6 6}$. O processo se completa com o tratamento com ácido fumárico, que fornece 59 cristalino em um rendimento global de apenas $13 \%$.

Nessa rota sintética há a necessidade de preparo prévio do carbonato quiral 61, que pode ser obtido em duas etapas adicionais a partir de $S$-glicidol (rendimento global de $70 \%)^{64}$ ou via fluxo contínuo a partir do glicerol, usando uma abordagem quimio-enzimática, em sete etapas sequenciais e $20 \%$ de rendimento global. ${ }^{65}$ Além disso, na primeira etapa dessa rota observa-se uma perda de seletividade devido à formação de outros regioisômeros $\mathrm{N}$-alquilados. ${ }^{66}$ Outros pontos carentes de melhoria nesse processo são a substituição do brometo de trimetilsilano (TMSBr), de elevado custo, por outro agente de dealquilação e o melhoramento dos processos de workup e isolamento de intermediários, nos estágios finais da síntese do pró-fármaco $\mathbf{5 9}$.

Em 2010, Ripin e colaboradores, ao revisitarem a rota sintética, alcançaram aumentos significativos do rendimento global da síntese<smiles>CCOP(=O)(COC(C)Cn1cnc2c(N)ncnc21)OCC(C)(C)Cn1cnc2c(N)ncnc21</smiles>

(59)<smiles>[R]P([R])(=O)CO[C@H](C)Cn1cnc2c(N)ncnc21</smiles>

(66)

$\mathrm{R}=\mathrm{CH}_{2} \mathrm{OCO}_{2} \mathrm{CH}(\mathrm{Me})_{2}$<smiles>CC(C)OC(=O)OCCl</smiles>

(65)

Esquema 26. Rota comercial de síntese do fumarato de Tenofovir desoproxila 
do composto 59 para $24 \%{ }^{62}$ e, posteriormente, para $31 \% .{ }^{67}$ No primeiro relato, os pesquisadores identificaram que a qualidade da base terc-butóxido de magnésio $\left(\mathrm{Mg}(\mathrm{O} t \mathrm{Bu})_{2}\right)$ é crucial na eficiência da etapa de $O$-alquilação do intermediário 63 e reduziram ainda o custo associado à etapa de desalquilação de $\mathbf{6 4}$ ao substituir $\mathrm{TMSBr}$ por uma mistura de $\mathrm{TMSCl} / \mathrm{NaBr}$. Além disso, para a etapa de esterificação do hidrato de Tenofovir (65), importantes melhorias foram alcançadas, como a adição de brometo de tetrabutilamônio, capaz de atuar como agente de transferência de fase, aumentar a velocidade de reação e estabilizar o produto formado $\mathbf{6 6}$, minimizando a formação de impurezas. Um outro ponto importante foi o emprego de ciclo-hexano no processo de extração do produto, reduzindo processos de decomposição.

Já na segunda publicação, os autores relataram o desenvolvimento de um procedimento one-pot para a conversão de 64 a 65 (Esquema 27). A hidrólise do éster fosfonato dietílico tem início com a sililação reversível de $\mathbf{6 4} \mathrm{com} \mathrm{TMSCl}$, gerando o intermediário reativo 67, o qual é então hidrolisado pelo íon brometo proveniente do $\mathrm{NaBr}$. O método utiliza condições brandas, capazes de promover ganhos importantes no tempo (12 horas) e temperatura reacionais $\left(60^{\circ} \mathrm{C}\right)$. Os pesquisadores demonstraram ainda a subsequente alquilação de $\mathbf{6 5}$ mediada por cloreto de metilisopropilcarbonato.

Dentro da mesma perspectiva de melhoramento da rota industrial de produção do pró-farmaco fumarato de Tenofovir desoproxila (59), Edlin e colaboradores reportaram uma série de modificações capazes de elevar o rendimento global da síntese para $23 \% .{ }^{68}$ Foi demonstrado que a substituição de bases de sódio pelas de potássio é benéfica para a etapa de $N$-alquilação da adenina (60) com o carbonato de $(R)$-propileno (61). Além disso, a substituição do $\mathrm{Mg}(\mathrm{O} t \mathrm{Bu})_{2}$, que além de possuir alto custo também necessita um alto grau de pureza e gera subprodutos de difícil isolamento e purificação, pela combinação na razão 1:1 de um reagente de Grignard ( $\mathrm{PhMgCl}$ ou $\mathrm{MeMgCl})$ e terc-butanol melhora significativamente a etapa de produção do intermediário 64.
Em 2014, outro trabalho trouxe inovações importantes no processo de síntese do Tenofovir, utilizando etapa de hidrogenação assimétrica a partir de derivados de purina para geração centro estereogênico (Esquema 28). ${ }^{69}$ Assim, a proposta foi a primeira a utilizar substratos aquirais como material de partida para preparação do intermediário-chave 63, uma vez que até então todas as alternativas de síntese disponíveis utilizavam de derivados enantiomericamente enriquecidos, como o composto 61. Merece destaque ainda que o protocolo utilizou condições reacionais brandas e forneceu o intermediário éster fosfonato $\mathbf{6 4} \mathrm{em} 97 \%$ de e.e. e em $47 \%$ de rendimento global. Por outro lado, como principal desvantagem, destaca-se o custo associado dos catalisadores.

Atualmente, a síntese do intermediário-chave quiral 63 também já foi descrita utilizando catálise enzimática, acessando o composto desejado em até $97 \%$ de rendimento e $99 \%$ de e.e. ao se utilizar cetoredutases. ${ }^{70}$

Em 2015, Jamison e colaboradores descreveram a síntese do hidrato de Tenofovir 65 em três etapas, a partir do dioxolano 68 (Esquema 29). ${ }^{71} \mathrm{O}$ protocolo consistiu na preparação da subunidade éter fosfonometílico presente em $\mathbf{7 0}$ via acoplamento do dioxolano na presença de bis(dietilamino)clorofosfina (69) e catálise por ácido de Lewis $\left(\mathrm{Zn}(\mathrm{OTf})_{2}\right)$, seguido de rearranjo. Na sequência, a adenina $(\mathbf{6 0})$ foi então $N$-alquilada com 70 na presença de $\mathrm{K}_{3} \mathrm{PO}_{4}$ e, após hidrólise ácida, o hidrato do Tenofovir $\mathbf{6 5}$ foi obtido em $27 \%$ de rendimento global. Além de utilizar condições brandas, materiais de partida acessíveis, e ser uma sequência curta, a metodologia é inovadora nas desconexões e em sua potencial aplicação sintética, uma vez que a subunidade $\mathbf{7 0}$ encontra-se presente também nas estruturas de outros antirretrovirais.

Em 2016, o grupo de pesquisa de Fan desenvolveu e aplicou um novo protocolo de hidrogenação assimétrica da nucleobase $\alpha$-purínica substituída $\mathbf{7 1}$ na síntese de um análogo do intermediáriochave do Tenofovir (73). ${ }^{72}$ Utilizando uma baixa carga de um catalisador de ródio com o ligante quiral $(R)$-Synphos, sob

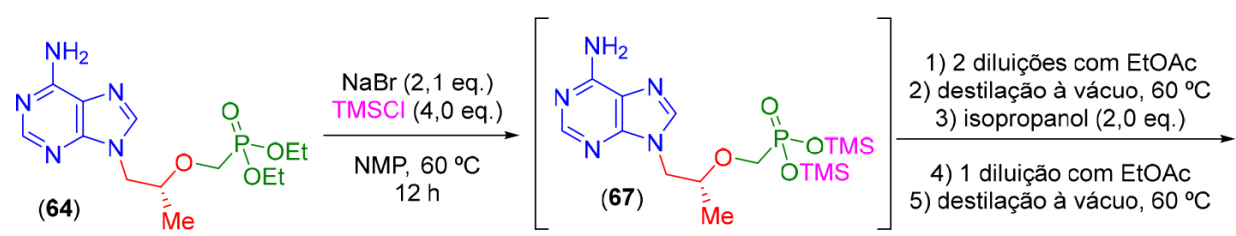

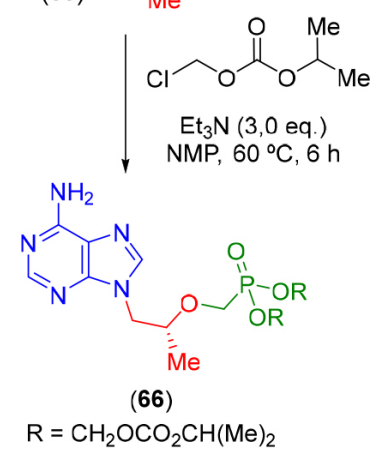

Esquema 27. Hidrólise one-pot do intermediário 64
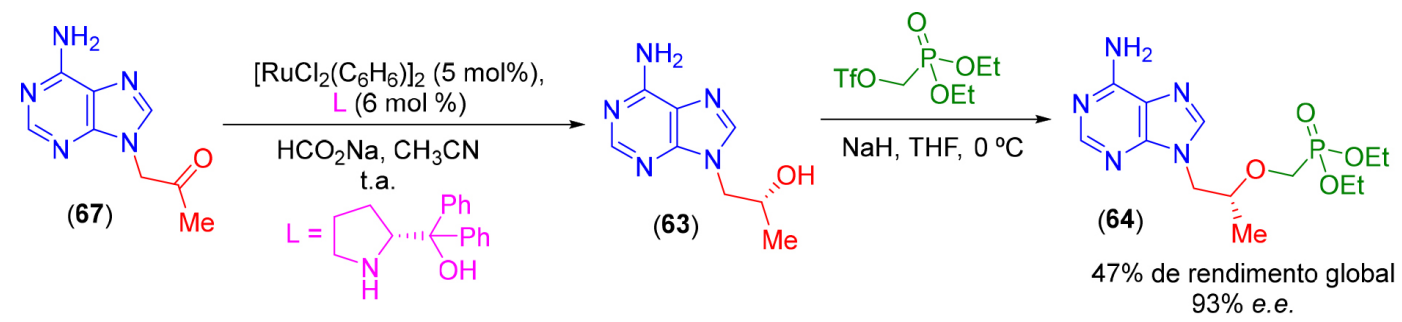

Esquema 28. Síntese do intermediário 64 via transferência de hidrogênio assimétrica 


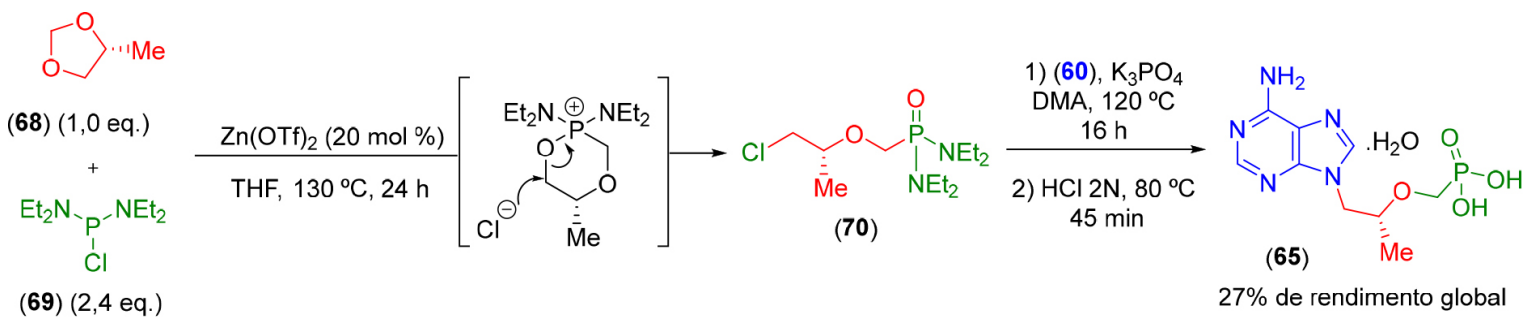

Esquema 29. Sintese do hidrato de Tenofovir utilizando o dioxolano 68 como material de partida

condições reacionais brandas, foi possível a obtenção do derivado 72 em excelente rendimento e excesso enantiomérico. Sua posterior conversão no análogo de um intermediário Tenofovir (73) foi ainda demonstrada em duas etapas, em $46 \%$ de rendimento e sem perda da enantiosseletividade (Esquema 30).

Em 2020, Gupton, McQuade e colaboradores apresentaram uma proposta inovadora de síntese para o Tenofovir (2), utilizando materiais de partida e intermediário-chave bastante distintos das rotas usuais (Esquema 31). ${ }^{60}$ Inicialmente, a condensação entre diaminomaleonitrila (74) e ortoformato de trimetila (75) forneceu o formimidato $\mathbf{7 6}$ em $93 \%$ de rendimento. Na sequência, a adição do (R)-1-aminopropan-2-ol (77), levou a um intermediário formamidino que, após ciclização, forneceu o $(R)$-5-amino-1(2-hidroxipropil)-1H-imidazol-4-carbonitrila (78) em $85 \%$ de rendimento. A seguir, a reação de $\mathbf{7 8}$ com acetato de formamidina resultou na formação do núcleo adenina presente em $\mathbf{6 3}$ em $93 \%$ de rendimento. Finalmente, a introdução da ligação fosfonato para formação de Tenofovir foi realizada pela $O$-alquilação via ácido tosiloximetil-fosfônico. Esse protocolo de quatro etapas forneceu o antiviral em $51 \%$ de rendimento global e tem potencial para escalonamento e realização via fluxo contínuo. Além disso, cabe ressaltar que, comparado ao processo comercial usual, uma melhoria satisfatória apresentada por este protocolo é a realização da $O$-alquilação de 63 em uma única etapa, em $70 \%$ de rendimento, utilizando $\mathrm{NaO} t \mathrm{Bu}$ como base.

Em 2020, Clososki e colaboradores ${ }^{9}$ optaram por utilizar a rota sintética otimizada por Ripin ${ }^{62,67}$ para obter fumarato de Tenofovir desoproxila em escala piloto, monitorando o processo de produção do antiviral por espectroscopia na região do infravermelho (IV). Estudos de degradação acelerada desse fármaco levaram ainda os pesquisadores a identificar um novo possível produto de degradação. Merece destaque que os autores reportaram a primeira investigação in vitro do Tenofovir frente à linhagens de SARS-CoV-2.

Recentemente, Opatz e colaboradores concentraram seus esforços na síntese dos fosfonatos de di-terc-butila 79 e 80 e na sua aplicação na síntese do Tenofovir, a partir do substrato $\mathbf{6 3}$, em uma sequência de duas etapas (Esquema 32). ${ }^{73}$ Primeiramente, as condições reacionais da alquilação do intermediário-chave 63 com o fosfonato na presença de $\mathrm{Mg}(\mathrm{O} t \mathrm{Bu})_{2}$ foram otimizadas, seguida de uma hidrólise ácida. Como vantagens, destaca-se que novos fosfonatos podem ser obtidos em larga escala e não necessitam de purificação por cromatografia. Adicionalmente, o emprego do derivado mesilado 79 conferiu uma maior economia atômica ao processo e forneceu o Tenofovir em $72 \%$ de rendimento numa reação conduzida numa escala de $5 \mathrm{~g}$ de $\mathbf{6 3}$.

\section{MOLNUPIRAVIR (EIDD-2801)}

O Molnupiravir, também denominado de EIDD-2801 ou MK4482, é uma das substâncias com potencial para o tratamento da COVID-19 desenvolvida pelo Instituto Emory para o desenvolvimento de medicamentos (Emory Institute for Drug Development). ${ }^{74-76}$ Essa substância é um pró-fármaco do EIDD-1931 que, apesar de manifestar uma boa atividade antiviral, não apresentou uma boa

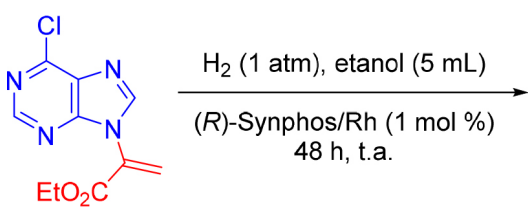

(71)<smiles>CCOC(=O)COCC(C)n1cnc2c(N)ncnc21</smiles>

(72)

$97 \%$ $93 \%$ e.e.
(73)

$46 \%$

Esquema 30. Síntese do análogo do intermediário-chave do Tenofovir 73

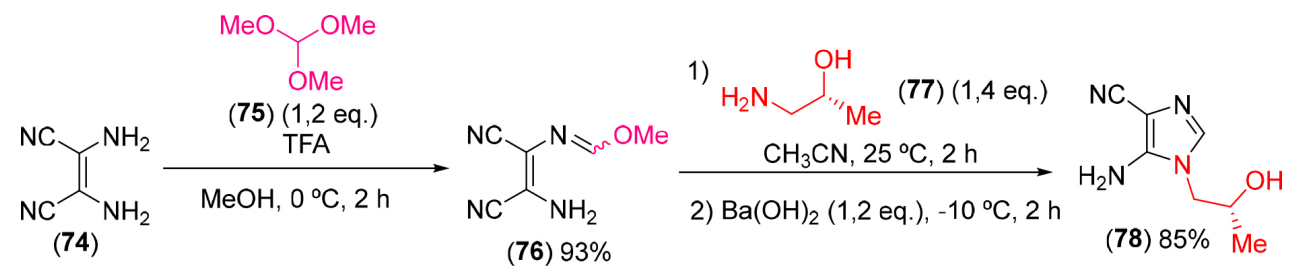

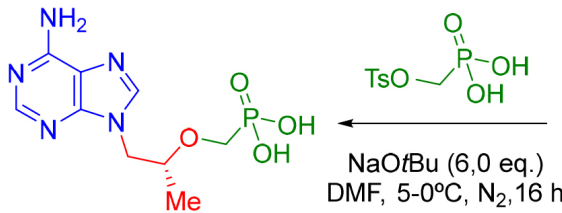

(Tenofovir) $70 \%$<smiles>CC(O)Cn1cnc2c(N)ncnc21</smiles>

(63) $93 \%$

Esquema 31. Síntese alternativa do Tenofovir 


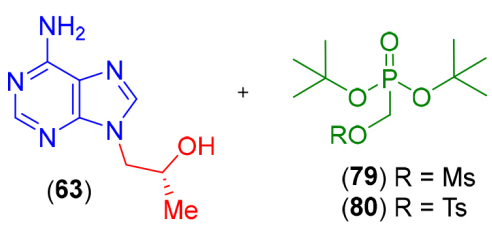

Esquema 32. Síntese do Tenofovir utilizando diferentes fosfonatos
1) $\mathrm{Mg}(\mathrm{OtBu})_{2}(3,0$ eq. $)$

DMA $[0,4 \mathrm{M}]$

$90^{\circ} \mathrm{C}, 21-24 \mathrm{~h}$

2) $\mathrm{H}_{2} \mathrm{SO}_{4} 3 \mathrm{~N}, 60^{\circ} \mathrm{C}, 2 \mathrm{~h}$

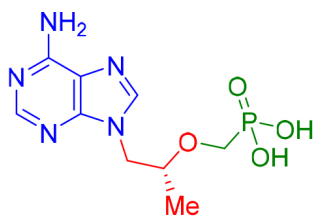

(Tenofovir)

$72 \%$; escala: $5,0 \mathrm{~g}$ a partir de 79

$68 \%$; escala: $1,0 \mathrm{~g}$ a partir de 80 biodistribuição em macacos. ${ }^{77} \mathrm{O}$ EIDD-2801 apresenta uma estrutura química mais simples que a do Remdesivir e ainda tem a vantagem de poder ser administrado pela via oral. Devido ao grande potencial dessa substância, recentemente, muitas propostas metodológicas de síntese vêm sendo desenvolvidas visando obtê-lo de maneira eficiente e acessível.

Painter e colaboradores publicaram, em 2019 pela Emory University, duas patentes reivindicando uma metodologia para síntese total do Molnupiravir. ${ }^{78,79}$ Essa proposta foi descrita em cinco etapas partindo da uridina $(\mathbf{8 1})$ e apresentou rendimento global inferior a 17\% (Esquema 33). A metodologia se iniciou com a proteção das hidroxilas secundárias da uridina com acetona em meio ácido, formando o intermediário 82. Em seguida, ocorreu a acilação deste intermediário com o anidrido isobutírico (83) catalisado por 4-DMAP na presença de trietilamina, levando ao intermediário 84 em $99 \%$ de rendimento. Na sequência, esse derivado foi então tratado com 1,2,4-triazol em meio básico na presença de $\mathrm{POCl}_{3}$ formando o intermediário $\mathbf{8 5}$ (29\% de rendimento). Finalmente, $\mathbf{8 5}$ sofre uma adição de hidroxilamina seguida da eliminação do triazol formando o intermediário 86 em $60 \%$ de rendimento, que após um tratamento ácido para desproteção das hidroxilas secundárias, leva ao Molnupiravir (3).

No ano seguinte, Snead e colaboradores publicaram novas propostas de metodologias para síntese total do Molnupiravir, em apenas duas etapas, partindo da citidina $(\mathbf{8 7})$ e com rendimentos globais entre $37-75 \% .{ }^{80}$ As metodologias propostas por Snead e colaboradores forneceram algumas vantagens importantes frente a metodologia anterior, como o menor custo da citidina (cerca de $40 \%$ do valor da uridina) e o menor número de etapas, decorrente da ausência de manipulação de grupos protetores. A primeira metodologia descrita por Snead partiu da esterificação seletiva da hidroxila primária da citidina utilizando $\mathbf{8 8}$ como doador de grupo acila, levando ao produto desejado $\mathbf{8 9}$ e também ao derivado $O, N$-diacilado como subproduto (Esquema 34A). Ao utilizarem o transferidor de grupo acila 91 e uma enzima como biocatalisador, a esterificação pode ser demonstrada tanto na primeira etapa como na segunda etapa da síntese. Quando a esterificação ocorreu na primeira etapa foi possível obter um rendimento de $78 \%$. A etapa seguinte de transaminação processou-se utilizando o sulfato de hidroxilamina em álcool isopropílico, gerando o produto em 96\% de rendimento (Esquema 34C). Na segunda metodologia, primeiro ocorreu a transaminação na presença de $\mathrm{NH}_{2} \mathrm{OH}$.OHAc, formando o intermediário $92 \mathrm{em} \mathrm{50 \%} \mathrm{de} \mathrm{rendimento,} \mathrm{seguida} \mathrm{da}$ reação com 91, fornecendo o Molnupiravir em 74\% de rendimento (Esquema 34D).

Os autores ainda sugeriram a obtenção do intermediário 92 a partir da uridina (Esquema 35). Nessa proposta, a uridina foi tratada com trietilamina na presença de TMSCl, seguida da reação com $\mathrm{POCl}_{3} \mathrm{e}$ 1,2,4-triazol, fornecendo o intermediário $93 \mathrm{em} 86 \%$ de rendimento. O intermediário foi então tratado com cloridrato de hidroxilamina na presença de acetato de sódio e forneceu o produto desejado $92 \mathrm{em}$ $76 \%$ de rendimento e $48 \%$ de rendimento global.

Recentemente, o grupo de Snead publicou uma nova rota de síntese partindo da citidina e minimizando algumas das desvantagens sintéticas da proposta de síntese anterior, como necessidade de uso de excesso do agente de acilação e o alto custo associado à enzima suportada. ${ }^{81}$ Inicialmente, os autores propuseram a proteção das hidroxilas secundárias da citidina com um acetonídeo

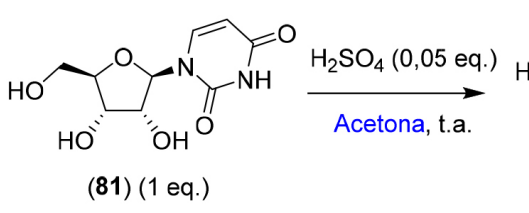<smiles>CC1(C)O[C@@H]2[C@H](O1)[C@H](n1ccc(=O)[nH]c1=O)O[C@@H]2CO</smiles>

(82)

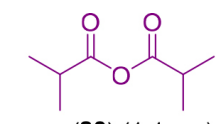

(83) $(1,1$ eq. $)$

Trietilamina (5 eq.) 4-DMAP $(0,05$ eq. $)$ $0{ }^{\circ} \mathrm{C}$
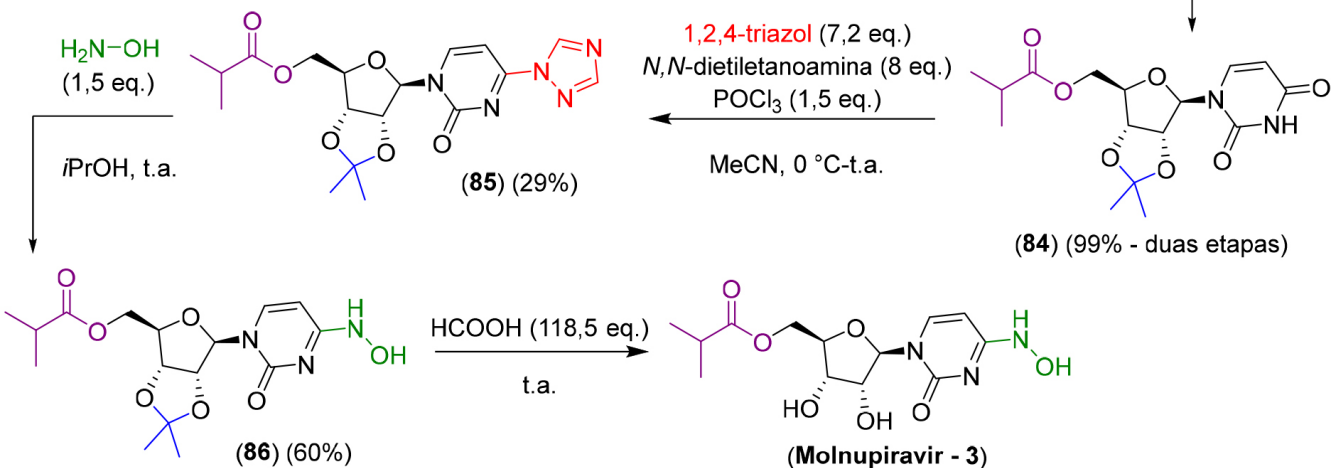<smiles>CC(C)C(=O)OC[C@H]1O[C@@H](n2ccc(NO)nc2=O)[C@H](O)[C@@H]1O</smiles>

(Molnupiravir - 3)

(rendimento não reportado)

Esquema 33. Metodologia de síntese total do Molnupiravir em cinco etapas partindo da uridina 
A)<smiles>Nc1ccn(C2OC(CO)[C@@H](O)[C@H]2O)c(=O)n1</smiles>

B)

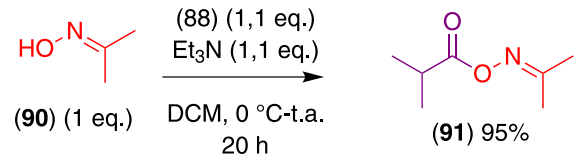<smiles>CC(C)C(=O)OCC1OC(n2ccc(N)nc2=O)[C@H](O)[C@@H]1O</smiles>

(89) $76 \%$

C)<smiles>Nc1ccn(C2OC(CO)[C@@H](O)[C@H]2O)c(=O)n1</smiles>

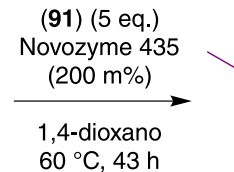
$60^{\circ} \mathrm{C}, 43 \mathrm{~h}$<smiles>CC(C)C(=O)OC[C@H]1O[C@@H](n2ccc(N)nc2=O)[C@H](O)[C@@H]1O</smiles>
$\mathrm{NH}_{2} \mathrm{OH} . \mathrm{H}_{2} \mathrm{SO}_{4}$ (4,5 eq.) $\mathrm{iPrOH}, 78^{\circ} \mathrm{C}, 20 \mathrm{~h}$ (89) $78 \%$<smiles>CC(C)C(=O)OC[C@H]1OC(n2ccc(NO)nc2=O)[C@H](O)[C@@H]1O</smiles>

(Molnupiravir) 96\%<smiles>Nc1ccn(C2O[C@H](CO)[C@@H](O)[C@H]2O)c(=O)n1</smiles><smiles>O=c1nc(NO)ccn1C1OC(CO)[C@@H](O)C1O</smiles>
(91) (3 eq.) Novozyme 435 (87) (1 eq.) $40^{\circ} \mathrm{C}, 48 \mathrm{~h}$

(92) $50 \%$<smiles>CC(C)C(=O)OC[C@H]1O[C@@H](n2ccc(N[14CH3])nc2=O)[C@H](O)[C@@H]1O</smiles>

(Molnupiravir) $74 \%$

Esquema 34. A) Acilação química da citidina; B) Síntese do doador de grupo acila 91; C) Síntese do Molnupiravir em duas etapas (acilação/transaminação); D) Síntese do Molnupiravir em duas etapas (transaminação/acilação)

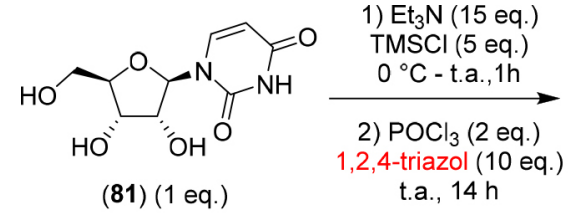

(81) (1 eq.)<smiles>O=c1nc(-n2cncn2)ccn1[C@@H]1O[C@H](CO)[C@@H](O)[C@H]1O</smiles>

(93) $86 \%$

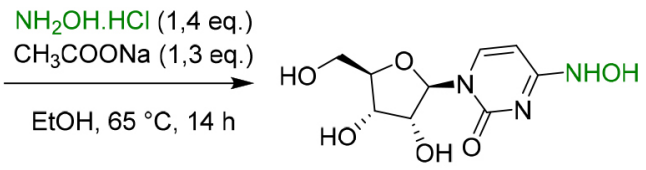

(92) $76 \%$

Esquema 35. Metodologia de síntese do intermediário 92 partindo da uridina em duas etapas

de maneira a diminuir a probabilidade de $O$-acilação e facilitar a separação da fase aquosa durante o processo de síntese (Esquema 36). Essa reação ocorreu na presença de acetona catalisada por ácido sulfúrico e forneceu o sal de sulfato do acetonídeo $94 \mathrm{em}$ $98 \%$ de rendimento, separado por precipitação diretamente do bruto reacional. Na sequência, a acilação foi realizada na presença de anidrido isobutírico catalisado por DMA e DBU fornecendo o intermediário 95 em $78 \%$ de rendimento. A reação de transaminação com hidroxilamina ocorreu de maneira a conservar o grupo isobutilester e formar o produto desejado $86 \mathrm{em} 96 \%$ de rendimento, seguido da desproteção do acetonídeo (60\% de rendimento). Uma alternativa demonstrada foi a realização dessas duas últimas etapas via one-pot, contudo foi observado a formação de $20 \%$ de $\mathrm{N}$-hidroxicitidina como subproduto. Nesse sentido, tanto a rota de duas etapas como a rota em um único frasco reacional para a acilação forneceram rendimentos globais bastante similares, 44 e $41 \%$ respectivamente.

Em 2020, Kappe e colaboradores demonstraram alterações na metodologia original de síntese do Molnupiravir e obtiveram um rendimento global de $61 \%$ partindo da uridina (Esquema 37 ). ${ }^{82}$ A síntese se iniciou pela etapa de triazolação que foi realizada na presença da base $N$-metilpirrolidina, além da proteção com TMSCl que foi retirado de maneira one-pot fornecendo o produto $93 \mathrm{em} 88 \%$ de rendimento por precipitação. Na etapa subsequente, observou-se que a necessidade de uso de um excesso de anidrido isobutírico estava relacionada a reações laterais com metanol (formado como subproduto da reação com 2,2-dimetóxipropano). Assim, ao realizar uma destilação azeotrópica para a remoção do metanol foi possível utilizar apenas 1,1 equivalentes de anidrido isobutírico, levando ao intermediário $\mathbf{8 5}$ de maneira quantitativa. A etapa seguinte foi 


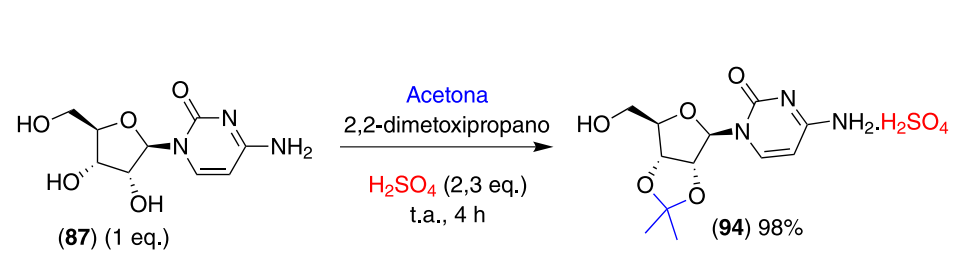

$\operatorname{DBU}(2,1$ eq. $)$

DMAP (20 mol\%)

Anidrido isobutírico

(1,1 eq.)

t.a., $\mathrm{MeCN}, 16 \mathrm{~h}$

(87) (1 eq.)

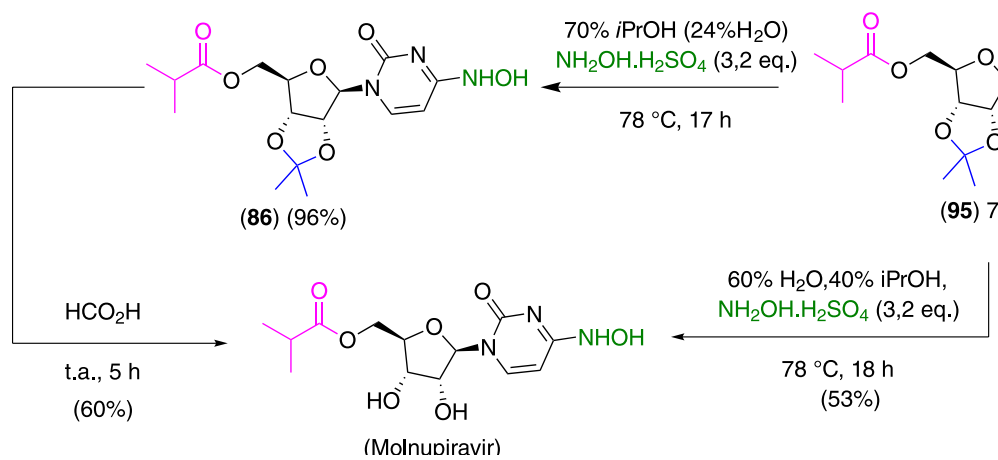

Esquema 36. Metodologia de síntese do Molnupiravir em quatro ou três etapas partindo da citidina
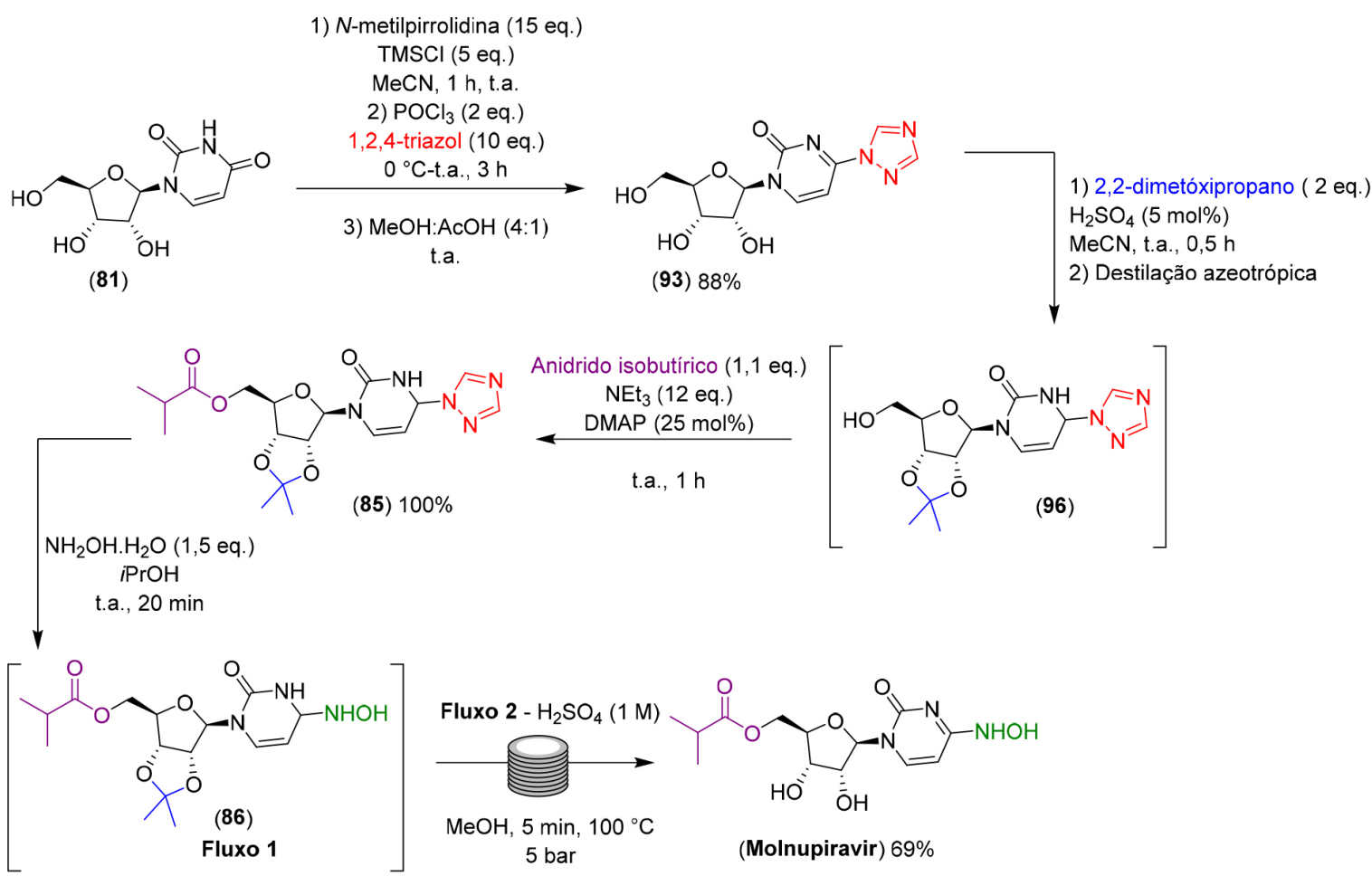

Esquema 37. Metodologia de síntese total em três etapas do Molnupiravir partindo da uridina

realizada em um sistema de fluxo contínuo, no qual o bruto da reação de 85 com a hidroxilamina foi inserido no reator. Foi necessário adicionar metanol para evitar a formação de precipitados dentro do reator, levando a um rendimento de $69 \%$.

Em 2021, Jamison, Snead e colaboradores revisitaram a proposta de síntese a partir da citidina ${ }^{80}$ e refinaram parâmetros de maneira a possibilitar uma escala sintética de decagramas (Esquema 38). ${ }^{83} \mathrm{Com}$ essa estratégia, foi possível obter um rendimento global de $41 \%$, sem a necessidade de purificações por cromatografia em coluna. A estratégia foi desenvolver uma metodologia de síntese acessível para a obtenção da oxima 90 a partir da acetona e cloridrato de hidroxilamina, fornecendo o intermediário desejado em $73 \%$ de rendimento e em uma escala de $500 \mathrm{~g}$. A etapa de acilação foi então conduzida numa escala de $200 \mathrm{~g}$, fornecendo o produto $\mathbf{8 9} \mathrm{em} 90 \%$ de rendimento.
Uma observação importante consistiu na possibilidade de reuso da enzima, reduzindo os custos associados a essa reação. Na etapa de transaminação (realizada a partir de $80 \mathrm{~g}$ de 89), substituiu-se a solução de isopropanol por uma solução de 1-butanol e diminuiu-se a equivalência do sal de hidroxilamina ( 3 eq.) com o objetivo facilitar a purificação. A etapa de purificação foi então realizada através de extrações líquido-líquido, seguida de recristalização, levando ao Molnupiravir em 58\% de rendimento.

Recentemente, Fier e colaboradores descreveram uma metodologia de síntese em três etapas para a obtenção do Molnupiravir com $69 \%$ de rendimento global partindo da ribose. ${ }^{84} \mathrm{~A}$ ribose 28 é um material de partida mais simples do que a citidina e uridina já reportados para essa síntese. A proposta envolve etapas sucessivas empregando biocatálise, seguida de uma etapa final de formação da 
A)

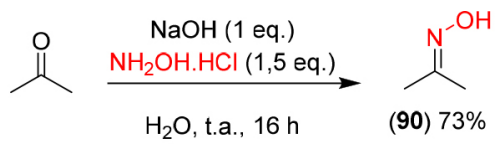

B)

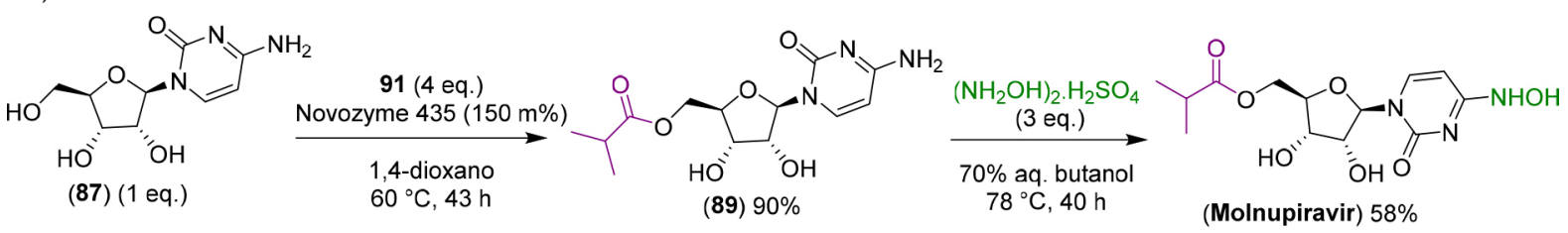

Esquema 38. A) Metodologia de síntese da oxima 90; B) Síntese em larga escala do Molnupiravir

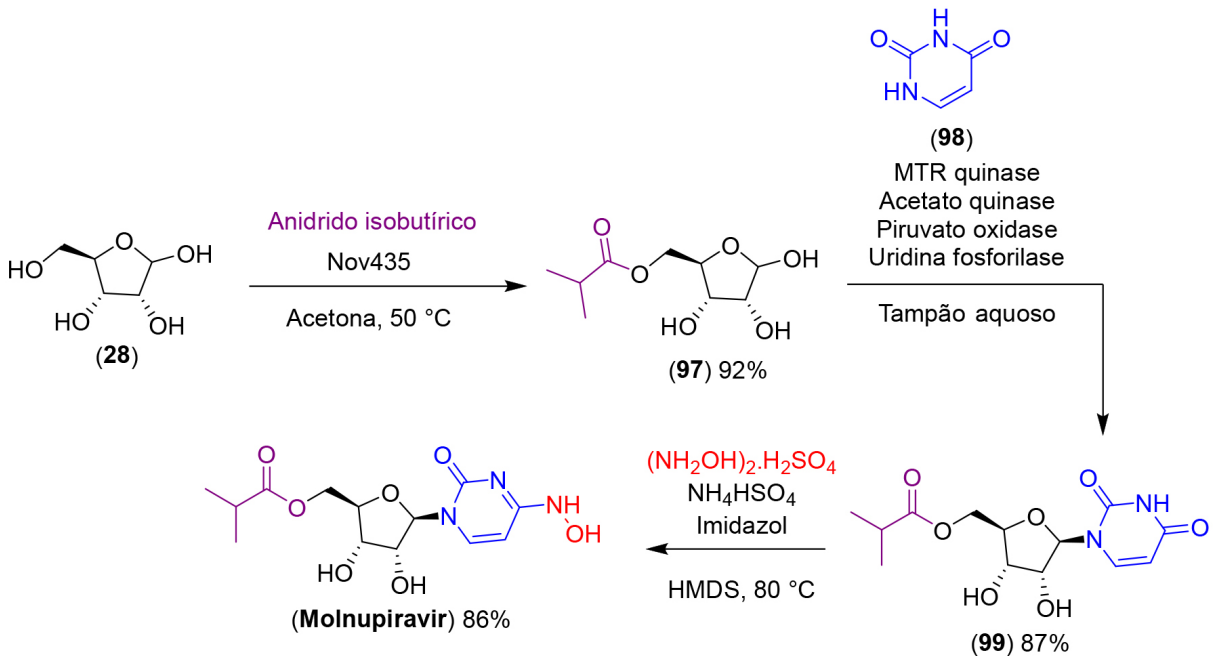

Esquema 39. Metodologia de síntese total do Molnupiravir em três etapas utilizando biocatálise

oxima (Esquema 39). A síntese se inicia pela acilação seletiva da hidroxila 5' da ribose com anidrido isobutírico na presença da enzima Nov435, seguida da fosforilação da hidroxila 1' com o auxílio da enzima MTR quinase e a substituição da uracila pela uridina fosforilase. Nessa reação as enzimas acetato quinase e piruvato oxidase atuam reciclando o ATP e evitando o acumulo de fósforo inorgânico que poderia deslocar o equilíbrio em direção a uracila livre. Finalmente a conversão da carbonila na oxima foi realizada através da reação de 99 com hidroxilamina, na presença de imidazol e hexametildisilazano (HMDS). O grupo TMS foi importante para facilitar o processo de purificação dos sais inorgânicos e foi facilmente retirado do sistema após ajuste do pH, fornecendo o EIDD-2801 em ótimo rendimento. Ressalta-se que essa estratégia de síntese mostrou-se bastante seletiva e forneceu altos rendimentos partindo de substratos bastante simples e acessíveis.

Green e colaboradores, em 2021, propuseram pela primeira vez uma metodologia biocatalítica para a síntese do intermediário $N$-hidroxicitidina (92) do Molnupiravir. ${ }^{85}$ A enzima citidina desaminase, responsável por converter a citinina em uridina, foi utilizada na presença da hidroxiamina, que atuou como nucleófilo ao invés da água. Nessas condições, foi verificado que o produto desejado 92 foi obtido na proporção de 4:1 em relação ao subproduto 81 (Esquema 40). Enzimas mutadas também foram avaliadas, sendo a mutação mais eficiente a T123G, que apresenta uma modificação próximo ao sítio ativo, levando a uma proporção de 6:1. Os autores não forneceram os rendimentos das reações, apesar de afirmarem que alcançaram bons rendimentos e que essa síntese tem aplicabilidade para ampliação de escala.

Em 2021, uma proposta sintética one-pot foi descrita partindo da citidina como material de partida, com $70 \%$ de rendimento

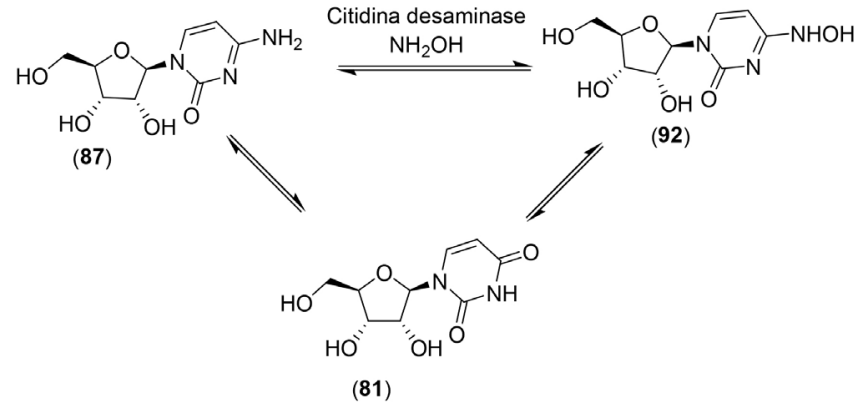

Esquema 40. Metodologia biocatalítica de síntese da N-hidroxicitidina 92

global (Esquema 41). ${ }^{49}$ A proposta iniciou com a utilização de $N, N$-dimetilformamida dimetil acetal (50) como grupo protetor do nitrogênio e das hidroxilas secundárias, levando ao intermediário 100. Após remoção do solvente, adicionou-se ao bruto reacional anidrido isobutírico, na presença de trietilamina e de DMAP catalítico, utilizando-se diclorometano como solvente. Na sequência, adicionou-se etanol à reação contendo o intermediário 101, resultando na formação de 102. Finalmente, uma nova remoção do solvente, seguida da adição de isopropanol e hidroxilamina levou à formação do molnupiravir em $70 \%$ de rendimento global. Essa metodologia é bastante inovadora por se tratar de uma metodologia via one-pot e que dispensa o uso de purificações por cromatografia em coluna.

\section{CONCLUSÕES}

A intensa busca por novos protocolos sintéticos para preparo dos antivirais Remdesivir, Molnupiravir e Tenofovir têm levado a um 
<smiles>Nc1ccn(C2OC(CO)[C@@H](O)[C@H]2O)c(=O)n1</smiles>

(87)

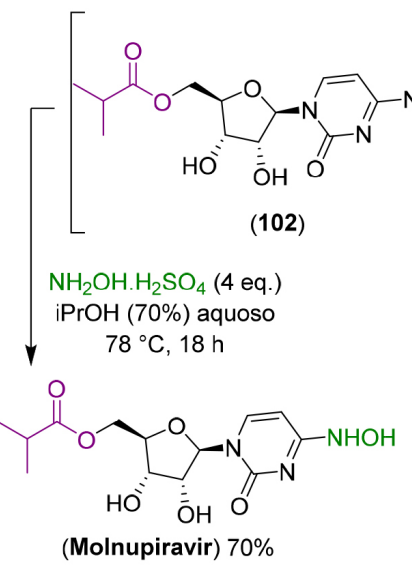

Esquema 41. Metodologia one-pot de síntese total do Molnupiravir

rápido desenvolvimento de novas alternativas para preparo dessas moléculas. No que diz respeito ao Remdesivir, estruturalmente mais complexo que os demais, os principais desafios sintéticos envolvem o preparo da base pirrolotriazina e as etapas de glicosilação, cianação assimétrica e fosforamidação da unidade carboidrato funcionalizada. Ferramentas sintéticas capazes de fornecer estratégias elegantes e reprodutíveis para o preparo alternativo desses compostos, como a catálise assimétrica, biocatálise, associadas à tecnologia em fluxo contínuo e desenvolvimento de processos one-pot têm surgido como alternativas promissoras de acessar esses três compostos. Apesar disso, as metodologias atuais ainda apresentam problemas importantes e são passíveis de melhoramentos, especialmente no que tange rendimentos, processos de purificação, uso de grupos protetores, e uso de reagentes de difícil manuseio e alto custo.

\section{AGRADECIMENTOS}

Os autores agradecem o apoio financeiro da CAPES (código 001), FAPEMIG (APQ-00341-20) e Rede Mineira de Química. Os autores agradecem também ao Conselho Nacional de Desenvolvimento Científico e Tecnológico - CNPq pelas bolsas concedidas a P. P. de Castro (No. 150082/2020-7) e a G. W. Amarante (No 310514/2018-5).

\section{REFERÊNCIAS}

1. De Clercq, E.; Li, G.; Clin. Microbiol. Rev. 2016, 29, 695.

2. Leite, D. I.; Faria, J. V.; de Azevedo, L. D.; Figueiredo, Y. V.; Martins, W. A.; Bianco, M. da C. A. D.; Bernardino, A. M. R.; Bastos, M. M.; Boechat, N.; Rev. Virtual Quim. 2015, 7, 2347.

3. Hardy, M. A.; Wright, B. A.; Bachman, J. L.; Boit, T. B.; Haley, H. M. S.; Knapp, R. R.; Lusi, R. F.; Okada, T.; Tona, V.; Garg, N. K.; Sarpong, R.; ACS Cent. Sci. 2020, 6, 1017.

4. Dömling, A.; Gao, L.; Chem 2020, 6, 1283.

5. Hashemian, S. M.; Farhadi, T.; Velayati, A. A.; Drug Des. Devel. Ther. 2020, 14,3215 .

6. Eastman, R. T.; Roth, J. S.; Brimacombe, K. R.; Simeonov, A.; Shen, M.; Patnaik, S.; Hall, M. D.; ACS Cent. Sci. 2020, 6, 672.

7. Sreekanth Reddy, O.; Lai, W.; ChemBioChem 2021, 22, 939.
8. Zanella, I.; Zizioli, D.; Castelli, F.; Quiros-Roldan, E.; Pharmaceuticals 2021, 14, 454.

9. Clososki, G. C.; Soldi, R. A.; da Silva, R. M.; Guaratini, T.; Lopes, J. N. C.; Pereira, P. R. R.; Lopes, J. L. C.; dos Santos, T.; Martins, R. B.; Costa, C. S.; de Carvalho, A. N.; daSilva, L. L. P.; Arruda, E.; Lopes, N. P.; J. Braz. Chem. Soc. 2020, 31, 1552.

10. Halford, B.; C\&EN Glob. Enterp. 2020, 98, 22.

11. Cox, R. M.; Wolf, J. D.; Plemper, R. K.; Nat. Microbiol. 2021, 6, 11.

12. Liang, C.; Tian, L.; Liu, Y.; Hui, N.; Qiao, G.; Li, H.; Shi, Z.; Tang, Y.; Zhang, D.; Xie, X.; Zhao, X.; Eur. J. Med. Chem. 2020, 201, 112527.

13. Al-Tannak, N. F.; Novotny, L.; Alhunayan, A.; Sci. Pharm. 2020, 88, 29.

14. Buckland, M. S.; Galloway, J. B.; Fhogartaigh, C. N.; Meredith, L.; Provine, N. M.; Bloor, S.; Ogbe, A.; Zelek, W. M.; Smielewska, A.; Yakovleva, A.; Mann, T.; Bergamaschi, L.; Turner, L.; Mescia, F.; Toonen, E. J. M.; Hackstein, C.-P.; Akther, H. D.; Vieira, V. A.; CeronGutierrez, L.; Periselneris, J.; Kiani-Alikhan, S.; Grigoriadou, S.; Vaghela, D.; Lear, S. E.; Török, M. E.; Hamilton, W. L.; Stockton, J.; Quick, J.; Nelson, P.; Hunter, M.; Coulter, T. I.; Devlin, L.; Bradley, J. R.; Smith, K. G. C.; Ouwehand, W. H.; Estcourt, L.; Harvala, H.; Roberts, D. J.; Wilkinson, I. B.; Screaton, N.; Loman, N.; Doffinger, R.; Lyons, P. A.; Morgan, B. P.; Goodfellow, I. G.; Klenerman, P.; Lehner, P. J.; Matheson, N. J.; Thaventhiran, J. E. D.; Nat. Commun. 2020, 11, 6385.

15. http://www.fda.gov/drugs/news-events-human-drugs/remdesivir-vekluryapproval-treatment-covid-19-evidence-safety-and-efficacy, acessada em agosto 2021.

16. http://www.gov.br/saude/pt-br/coronavirus/publicacoes-tecnicas/notastecnicas/nota-tecnica-rendesivir-covid-19, acessada em agosto 2021.

17. Byléhn, F.; Menéndez, C. A.; Perez-Lemus, G. R.; Alvarado, W.; de Pablo, J. J.; ACS Cent. Sci. 2021, 7, 164.

18. Kokic, G.; Hillen, H. S.; Tegunov, D.; Dienemann, C.; Seitz, F.; Schmitzova, J.; Farnung, L.; Siewert, A.; Höbartner, C.; Cramer, P.; Nat. Commun. 2021, 12, 279.

19. Yan, V. C.; Muller, F. L.; ACS Med. Chem. Lett. 2020, 11, 1361.

20. http://stories.gilead.com/articles/an-open-letter-from-daniel-odayjune-29, acessada em agosto 2021.

21. Patil, S. A.; Otter, B. A.; Klein, R. S.; J. Heterocycl. Chem. 1994, 31, 781. 
22. O’Connor, S.; Dumas, J.; Lee, W.; Dixon, J.; Cantin, D.; Gunn, D.; Burke, J.; Phillips, B.; Lowe, D.; Shelekhin, T.; Wang, G.; Ma, X.; Ying, S.; Mcclure, A.; Achebe, F.; Lobell, M.; Ehrgott, F.; Iwuagwu, C.; Parcella, K.; US Pat. US8431695B2 2006.

23. Dixon, J. A.; Phillips, B.; Achebe, F.; Kluender, H. C. E.; Newcom, J.; Parcella, K.; Magnuson, S.; Hong, Z.; Zhang, Z.; Liu, Z.; Khire, U.; Wang, L.; Michels, M.; Chandler, B.; O'Connor, S.; US Pat. US8143393B2 2006.

24. Paymode, D. J.; Cardoso, F. S. P.; Agrawal, T.; Tomlin, J. W.; Cook, D. W.; Burns, J. M.; Stringham, R. W.; Sieber, J. D.; Gupton, B. F.; Snead, D. R.; Org. Lett. 2020, 22, 7656.

25. Knapp, R. R.; Tona, V.; Okada, T.; Sarpong, R.; Garg, N. K.; Org. Lett. 2020, 22, 8430 .

26. dos Santos, J. A.; Pereira, V. R. D.; da Silva, A. D.; Amarante, G. W.; J. Braz. Chem. Soc. 2021, 32, 1391.

27. Siegel, D.; Hui, H. C.; Doerffler, E.; Clarke, M. O.; Chun, K.; Zhang, L.; Neville, S.; Carra, E.; Lew, W.; Ross, B.; Wang, Q.; Wolfe, L.; Jordan, R.; Soloveva, V.; Knox, J.; Perry, J.; Perron, M.; Stray, K. M.; Barauskas, O.; Feng, J. Y.; Xu, Y.; Lee, G.; Rheingold, A. L.; Ray, A. S.; Bannister, R.; Strickley, R.; Swaminathan, S.; Lee, W. A.; Bavari, S.; Cihlar, T.; Lo, M. K.; Warren, T. K.; Mackman, R. L.; J. Med. Chem. 2017, 60, 1648.

28. von Keutz, T.; Williams, J. D.; Kappe, C. O.; Org. Process Res. Dev. 2020, 24, 2362.

29. Souza Neto, P.; Guimarães, B.; Freitas, J.; Oliveira, R.; Freitas Filho, J.; Quim. Nova 2020, 44, 432.

30. Liao, H.; Ma, J.; Yao, H.; Liu, X.-W.; Org. Biomol. Chem. 2018, 16, 1791.

31. Patil, S. A.; Otter, B. A.; Klein, R. S.; Tetrahedron Lett. 1994, 35, 5339.

32. Butler, T.; Cho, A.; Graetz, B. R.; Kim, C. U.; Metobo, S. E.; Saunders, O. L.; Waltman, A. W.; Xu, J.; Zhang, L.; WO Pat. WO2011035250A1 2010.

33. Butler, T.; Cho, A.; Kim, C. U.; Parrish, J.; Saunders, O. L.; Zhang, L.; US Pat. US8008264B2 2009

34. Butler, T.; Cho, A.; Graetz, B. R.; Kim, C. U.; Metobo, S. E.; Saunders, O. L.; Waltman, A. W.; Xu, J.; Zhang, L.; US Pat. US10023600B2 2010.

35. Metobo, S. E.; Xu, J.; Jie; Saunders, O. L.; Butler, T.; Aktoudianakis, E.; Cho, C.; Kim, C. U.; Tetrahedron Lett. 2012, 53, 484.

36. Axt, S. D.; Badalov, P. R.; Brak, K.; Campagna, S.; Chtchemelinine, A.; Doerffler, E.; Frick, M. M.; Gao, D.; Heumann, L. V.; Hoang, B.; Lew, W.; Milburn, R. R.; Neville, S. T.; Ross, B.; Rueden, E.; Scott, R. W.; Siegel, D.; Stevens, A. C.; Tadeus, C.; Vieira, T.; Waltman, A. W.; Wang, X.; Whitcomb, M. C.; Wolfe, L.; Yu, C.-Y.; WO Pat. WO2016069825A1 2015.

37. Warren, T. K.; Jordan, R.; Lo, M. K.; Ray, A. S.; Mackman, R. L.; Soloveva, V.; Siegel, D.; Perron, M.; Bannister, R.; Hui, H. C.; Larson, N.; Strickley, R.; Wells, J.; Stuthman, K. S.; Van Tongeren, S. A.; Garza, N. L.; Donnelly, G.; Shurtleff, A. C.; Retterer, C. J.; Gharaibeh, D.; Zamani, R.; Kenny, T.; Eaton, B. P.; Grimes, E.; Welch, L. S.; Gomba, L.; Wilhelmsen, C. L.; Nichols, D. K.; Nuss, J. E.; Nagle, E. R.; Kugelman, J. R.; Palacios, G.; Doerffler, E.; Neville, S.; Carra, E.; Clarke, M. O.; Zhang, L.; Lew, W.; Ross, B.; Wang, Q.; Chun, K.; Wolfe, L.; Babusis, D.; Park, Y.; Stray, K. M.; Trancheva, I.; Feng, J. Y.; Barauskas, O.; Xu, Y.; Wong, P.; Braun, M. R.; Flint, M.; McMullan, L. K.; Chen, S.-S.; Fearns, R.; Swaminathan, S.; Mayers, D. L.; Spiropoulou, C. F.; Lee, W. A.; Nichol, S. T.; Cihlar, T.; Bavari, S.; Nature 2016, 531, 381 .

38. Xue, F.; Zhou, X.; Zhou, R.; Zhou, X.; Xiao, D.; Gu, E.; Guo, X.; Xiang, J.; Wang, K.; Yang, L.; Zhong, W.; Qin, Y.; Org. Process Res. Dev. 2020, 24,1772 .

39. von Keutz, T.; Williams, J. D.; Kappe, C. O.; Org. Process Res. Dev. 2021, 25, 1015.

40. Yoshida, J.; Takahashi, Y.; Nagaki, A.; Chem. Commun. 2013, 49, 9896.

41. Xie, Y.; Hu, T.; Zhang, Y.; Wei, D.; Zheng, W.; Zhu, F.; Tian, G.; Aisa, H. A.; Shen, J.; J. Org. Chem. 2021, 86, 5065.
42. Wang, W.; Liu, X.; Lin, L.; Feng, X.; Eur. J. Org. Chem. 2010, 2010, 4751 .

43. Kurono, N.; Ohkuma, T.; ACS Catal. 2016, 6, 989.

44. Vieira, T.; Stevens, A. C.; Chtchemelinine, A.; Gao, D.; Badalov, P.; Heumann, L.; Org. Process Res. Dev. 2020, 24, 2113.

45. De Savi, C.; Hughes, D. L.; Kvaerno, L.; Org. Process Res. Dev. 2020 24,940 .

46. Wang, Z.; Yang, L.; New J. Chem. 2020, 44, 12417.

47. Wang, M.; Zhang, L.; Huo, X.; Zhang, Z.; Yuan, Q.; Li, P.; Chen, J.; Zou, Y.; Wu, Z.; Zhang, W.; Angew. Chem., Int. Ed. 2020, 59, 20814.

48. Gannedi, V.; Villuri, B. K.; Reddy, S. N.; Ku, C.; Wong, C.; Hung, S.; J. Org. Chem. 2021, 86, 4977.

49. Hu, T.; Xie, Y.; Liu, Y.; Xue, H.; Zhu, F.; Aisa, H. A.; Shen, J.; ChemRxiv (2021), doi: 10.26434/chemrxiv.14208206.v1.

50. Benshun, C.; Tao, J.; Ping, Z.; Tao, Y.; CN Pat. CN111116656A 2020.

51. Benshun, C.; Tao, J.; Ping, Z.; Gang, C.; CN Pat. CN111233930A 2020.

52. Xuchun, Z.; Huaizhi, J.; Yiping, Z.; Chenchen, F.; Yihua, W.; CN Pat. CN111848679A 2020.

53. Machado, A. H. L.; Pandoli, O.; Miranda, L. S. M.; de Souza, R. O. M. A.; Rev. Virtual Quim. 2014, 6, 1076.

54. Benshun, C.; Liang, Z.; Bo, L.; Chao, C.; Yun, Z.; CN Pat. CN111171078A 2020.

55. Benshun, C.; Jinxing, Y.; Dawei, L.; Liping, S.; Chuntao, X.; Yi, C.; Weibing, Z.; Xiang, M.; Lingyi, Z.; Tao, J.; CN Pat. CN111471070A 2020.

56. Alavian, G.; Kolahdouzan, K.; Mortezazadeh, M.; Torabi, Z. S.; J. Clin. Pharmacol. 2021, 61, 581.

57. Ayerdi, O.; Puerta, T.; Clavo, P.; Vera, M.; Ballesteros, J.; Fuentes, M. E.; Estrada, V.; Rodríguez, C.; Del Romero, J.; Del Romero, J.; Rodríguez, C.; Puerta, T.; Clavo, P.; Vera, M.; Ballesteros, J.; Lejarraga, C.; Fernández, N.; Hurtado, E.; García, M.; González, M.; Jerez, N.; Alcudia, F.; Jiménez, M. T.; Torres, E.; de Domingo, I.; Lázaro, R.; Raposo, M.; Ayerdi, O.; Del Romero, J.; Rodríguez, C.; Puerta, T.; Clavo, P.; Vera, M.; Ballesteros, J.; Lejarraga, C.; Fernández, N.; Hurtado, E.; García, M.; González, M.; Jerez, N.; Alcudia, F.; Jiménez, M. T.; Torres, E.; de Domingo, I.; Lázaro, R.; Raposo, M.; Ayerdi, O.; Open Forum Infect. Dis. 2020, 7, ofaa455.

58. Mongia, A.; Saha, S. K.; Chouzenoux, E.; Majumdar, A.; Sci. Rep. 2021, $11,9047$.

59. Mandala, D.; Thompson, W. A.; Watts, P.; Tetrahedron 2016, 72, 3389.

60. Derstine, B. P.; Tomlin, J. W.; Peck, C. L.; Dietz, J.-P.; Herrera, B. T.; Cardoso, F. S. P.; Paymode, D. J.; Yue, A. C.; Arduengo, A. J.; Opatz, T.; Snead, D. R.; Stringham, R. W.; McQuade, D. T.; Gupton, B. F.; Org. Process Res. Dev. 2020, 24, 1420.

61. Arimilli, M. N.; Cundy, K. C.; Dougherty, J. P.; Kim, C. U.; Oliyai, R.; Stella, V. J.; US Pat. US5977089A 1999.

62. Brown Ripin, D. H.; Teager, D. S.; Fortunak, J.; Basha, S. M.; Bivins, N.; Boddy, C. N.; Byrn, S.; Catlin, K. K.; Houghton, S. R.; Jagadeesh, S. T.; Kumar, K. A.; Melton, J.; Muneer, S.; Rao, L. N.; Rao, R. V.; Ray, P. C.; Reddy, N. G.; Reddy, R. M.; Shekar, K. C.; Silverton, T.; Smith, D. T.; Stringham, R. W.; Subbaraju, G. V.; Talley, F.; Williams, A.; Org. Process Res. Dev. 2010, 14, 1194.

63. Arimilli, M. N.; Cundy, K. C.; Dougherty, J. P.; Kim, C. U.; Oliyai, R.; Stella, V. J.; US Pat. US5922695A 1999.

64. Bischofberger, N. W.; US Pat. US5733788A 1998.

65. Suveges, N. S.; Rodriguez, A. A.; Diederichs, C. C.; de Souza, S. P.; Leão, R. A. C.; Miranda, L. S. M.; Horta, B. A. C.; Pedraza, S. F.; de Carvalho, O. V.; Pais, K. C.; Terra, J. H. C.; de Souza, R. O. M. A.; Eur. J. Org. Chem. 2018, 2018, 2931.

66. Gao, Y.; Zhong, J.-L.; Wu, T.-Z.; Jin, L.-Y.; Zhang, F.-L.; J. Heterocycl. Chem. 2016, 53, 579

67. Houghton, S. R.; Melton, J.; Fortunak, J.; Brown Ripin, D. H.; Boddy, C. N.; Tetrahedron 2010, 66, 8137 . 
68. Riley, D. L.; Walwyn, D. R.; Edlin, C. D.; Org. Process Res. Dev. 2016, 20,742 .

69. Zhang, Q.; Ma, B.-W.; Wang, Q.-Q.; Wang, X.-X.; Hu, X.; Xie, M.-S.; Qu, G.-R.; Guo, H.-M.; Org. Lett. 2014, 16, 2014

70. Wang, Y.; Cao, Y.; Li, Y.; Jin, J.; Li, J.; Song, H.; Tetrahedron: Asymmetry 2017, 28, 745.

71. Ocampo, C. E.; Lee, D.; Jamison, T. F.; Org. Lett. 2015, 17, 820.

72. Sun, H.-L.; Chen, F.; Xie, M.-S.; Guo, H.-M.; Qu, G.-R.; He, Y.-M.; Fan, Q.-H.; Org. Lett. 2016, 18, 2260.

73. Dietz, J.-P.; Ferenc, D.; Jamison, T. F.; Gupton, B. F.; Opatz, T.; Org Process Res. Dev. 2021, 25, 789.

74. Sheahan, T. P.; Sims, A. C.; Zhou, S.; Graham, R. L.; Pruijssers, A. J.; Agostini, M. L.; Leist, S. R.; Schäfer, A.; Dinnon, K. H.; Stevens, L. J.; Chappell, J. D.; Lu, X.; Hughes, T. M.; George, A. S.; Hill, C. S.; Montgomery, S. A.; Brown, A. J.; Bluemling, G. R.; Natchus, M. G.; Saindane, M.; Kolykhalov, A. A.; Painter, G.; Harcourt, J.; Tamin, A.; Thornburg, N. J.; Swanstrom, R.; Denison, M. R.; Baric, R. S.; Sci. Transl. Med. 2020, 12, eabb5883.

75. Agostini, M. L.; Pruijssers, A. J.; Chappell, J. D.; Gribble, J.; Lu, X.; Andres, E. L.; Bluemling, G. R.; Lockwood, M. A.; Sheahan, T. P.; Sims, A. C.; Natchus, M. G.; Saindane, M.; Kolykhalov, A. A.; Painter, G. R.; Baric, R. S.; Denison, M. R.; J. Virol. 2019, 93, 1.

76. Wahl, A.; Gralinski, L. E.; Johnson, C. E.; Yao, W.; Kovarova, M. Dinnon, K. H.; Liu, H.; Madden, V. J.; Krzystek, H. M.; De, C.; White, K. K.; Gully, K.; Schäfer, A.; Zaman, T.; Leist, S. R.; Grant, P. O.; Bluemling, G. R.; Kolykhalov, A. A.; Natchus, M. G.; Askin, F. B.; Painter, G.; Browne, E. P.; Jones, C. D.; Pickles, R. J.; Baric, R. S.; Garcia, J. V.; Nature 2021, 591, 451.
77. Toots, M.; Yoon, J.-J.; Cox, R. M.; Hart, M.; Sticher, Z. M.; Makhsous, N.; Plesker, R.; Barrena, A. H.; Reddy, P. G.; Mitchell, D. G.; Shean, R. C.; Bluemling, G. R.; Kolykhalov, A. A.; Greninger, A. L.; Natchus, M. G.; Painter, G. R.; Plemper, R. K.; Sci. Transl. Med. 2019, 11, eaax5866.

78. Painter, G. R.; Bluemling, G. R.; Natchus, M. G.; Guthrie, D.; WO Pat. WO2019113462 2019.

79. Painter, G. R.; Perryman, D.; Bluemling, G. R.; WO Pat. WO2019173602 2019.

80. Vasudevan, N.; Ahlqvist, G. P.; McGeough, C. P.; Paymode, D. J.; Cardoso, F. S. P.; Lucas, T.; Dietz, J.-P.; Opatz, T.; Jamison, T. F.; Gupton, F. B.; Snead, D. R.; Chem. Commun. 2020, 56, 13363.

81. Gopalsamuthiram, V.; Williams, C.; Noble, J.; Jamison, T. F.; Gupton, B. F.; Snead, D. R.; Synlett 2021, 32, 326.

82. Steiner, A.; Znidar, D.; Ötvös, S. B.; Snead, D. R.; Dallinger, D.; Kappe, C. O.; Eur. J. Org. Chem. 2020, 2020, 6736.

83. Ahlqvist, G. P.; McGeough, C. P.; Senanayake, C.; Armstrong, J. D.; Yadaw, A.; Roy, S.; Ahmad, S.; Snead, D. R.; Jamison, T. F.; ACS Omega 2021, 6, 10396.

84. Benkovics, T.; McIntosh, J.; Silverman, S.; Kong, J.; Maligres, P.; Itoh, T.; Yang, H.; Huffman, M.; Verma, D.; Pan, W.; Ho, H.-I.; Vroom, J.; Knight, A.; Hurtak, J.; Morris, W.; Strotman, N.; Murphy, G.; Maloney, K.; Fier, P.; ChemRxiv (2020), doi: 10.26434/chemrxiv.13472373.v1.

85. Burke, A.; Birmingham, W.; Zhuo, Y.; da Costa, B. Z.; Crawshaw, R.; Thorpe, T.; Rowles, I.; Finnigan, J.; Charnock, S. J.; Lovelock, S.; Turner, N.; Green, A.; ChemRxiv (2021), doi: 10.26434/ chemrxiv.13721692.v1. 